Check for updates

Cite this: RSC Adv., 2017, 7, 54039

Received 6th September 2017

Accepted 18th November 2017

DOI: $10.1039 / c 7 r a 09940 a$

rsc.li/rsc-advances

\section{Polyethylenimine-functionalized cellulose aerogel beads for efficient dynamic removal of chromium(vı) from aqueous solution $\uparrow$}

\author{
Dong-Mei Guo, ${ }^{a}$ Qing-Da An, (D) *a Zuo-Yi Xiao, (D) ${ }^{a}$ Shang-Ru Zhai (D) *a \\ and Zhan Shi $\mathbb{D D}^{\mathrm{b}}$
}

For the highly effective removal of hexavalent chromium from aqueous solutions, a new polyethylenimine (PEI) grafted porous adsorbent, a cellulose(APEI aerogel (CPA-2) composite, was synthesized through a glutaraldehyde crosslinking reaction between the amine groups of $\mathrm{PEI}$ and the hydroxyl groups of cellulose. The physicochemical properties of this new adsorbent were characterized by FT-IR, SEM, EDX, XPS, etc., and the modification of grafting with PEI was demonstrated by FT-IR, EDX and XPS analyses. The effects of $\mathrm{pH}$, contact time, initial concentration and $\mathrm{PEI}$ content on $\mathrm{Cr}(\mathrm{VI})$ sorption were systematically investigated. Experimental data were well described by the Freundlich isotherm and the pseudo-second-order model in a batch system, demonstrating that chemisorption was the ratecontrolling factor for $\mathrm{Cr}(\mathrm{VI})$ removal with $\mathrm{CPA}-2$. Furthermore, the experimental maximum adsorption capacity of CPA-2 was $229.1 \mathrm{mg} \mathrm{g}^{-1}$, which was around 12 times higher than that of cellulose aerogel (CA) $\left(18.7 \mathrm{mg} \mathrm{g}^{-1}\right.$ ). The Thomas model was well fitted to the breakthrough curves of adsorption processes under different fixed-bed conditions. Above all, the exhausted bead-like adsorbent could be easily separated and regenerated without significant loss of adsorption capacity. Accordingly, this new composite material should be a promising sorbent for sewage disposal, with advantages of high performance, low-cost, biodegradability and excellent reusability.

\section{Introduction}

With the rapid development of industrialization and urbanization, water contamination such as heavy metal pollution has led to severe environmental problems, which threaten ecological systems and human health. Chromium, a heavy metal existing generally in sewage, usually originates from industries such as textile dyeing, leather tanning and paper making. ${ }^{1}$ There are two valences of chromium in its natural state, which are trivalence and hexavalence, having observable differences in toxicities. ${ }^{2}$ Trivalent chromium is an essential trace element that is good for metabolizing sugar, protein and fat (the quantity demanded is $50-200 \mathrm{mg}$ a day). ${ }^{3}$ Nevertheless, hexavalent chromium, which is highly soluble and mobile in aqueous media, exerts toxicity, carcinogenicity and mutagenicity to humans and animals because of its strong oxidizing properties. $^{4,5}$ Nowadays, the U.S. Environmental Protection Agency (EPA) Guidelines give a maximum value of chromium in potable

${ }^{a}$ Faculty of Light Industry and Chemical Engineering, Dalian Polytechnic University, Dalian 116034, China.E-mail: anqingdachem@163.com; zhaisrchem@163.com ${ }^{b}$ State Key Laboratory of Inorganic Synthesis and Preparative Chemistry, College of Chemistry, Jilin University, Changchun 130012, China

$\dagger$ Electronic supplementary information (ESI) available. See DOI: 10.1039/c7ra09940a

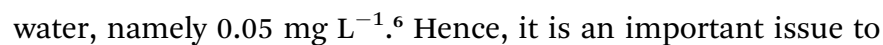
remove $\mathrm{Cr}(\mathrm{vI})$ from chromium-polluted water to weaken the grave impact of $\mathrm{Cr}(\mathrm{vI})$ on human health.

Numerous methods, including photocatalysis, ${ }^{7}$ membrane process, ${ }^{8}$ adsorption, ${ }^{\mathbf{9}, 10}$ electrochemical treatment ${ }^{\mathbf{1 1}}$ and so forth, have been used to remove $\mathrm{Cr}(\mathrm{vI})$ from wastewater. Nevertheless, most of these strategies have associated defects which more or less limit their practical application to sewage disposal, for instance, high cost produced by operating, poor efficacy, generation of a toxic sludge and secondary pollutants and so on. By contrast, adsorption is regarded as a simple and cost effective method for the separation of chromium from aqueous solutions, because of the simplicity of design, environmental friendliness, low cost, high efficiency and reusability of adsorbents. ${ }^{12}$

Up to now, a variety of adsorbents, such as graphene, ${ }^{13}$ biomass, ${ }^{14}$ activated carbon, ${ }^{3}$ mineral, ${ }^{15,16}$ etc., have been developed to dispose $\mathrm{Cr}(\mathrm{vI})$. Amongst them, using low-cost biomass as adsorbent to remove $\mathrm{Cr}(\mathrm{vI})$ has received great attention, such as rice husk, ${ }^{17}$ cellulose,${ }^{18}$ lignin, ${ }^{19}$ sodium alginate ${ }^{20}$ and chitosan. ${ }^{21}$ Among these materials, cellulose has received increasing attentions owing to its properties which contain inexpensive, abundant, non-toxic, low weight, renewable and biodegradable. There are many - $\mathrm{OH}$ groups on the surface of cellulose that can provide some adsorption capacity. 
However, previous powdery cellulose-based adsorbents are difficult to be separated from sewage, usually employing energyconsuming processes like filtration or centrifuging. ${ }^{22}$ To address this issue, the preparation of micrometer-sized cellulose aerogel beads might be an alternative way to solve this bottleneck problem. Moreover, as a result of the low activity of $-\mathrm{OH}$, the adsorption capacity of pure cellulose is little. Hence, surface modification of cellulose materials with more functional groups to significantly enhance the adsorption ability of adsorbent has attracted more and more attentions within the last decades.

Some effective groups such as carbonyl group, ${ }^{23}$ carboxyl group $^{24}$ and amino group ${ }^{25,26}$ can be grafted onto the surface of cellulose to improve the adsorption capacity. By contrast, amino-functionalized adsorbents exerted excellent properties in removing $\mathrm{Cr}(\mathrm{vI})$ ions from effluents. ${ }^{26}$ For example, Tian et al. reported a composite composed of halloysite and polyethyleneimine to dispose chromium-polluted water, and its maximum adsorbing capacity was $102.5 \mathrm{mg} \mathrm{g}{ }^{-1} \cdot{ }^{27}$ In addition, Chen et al. prepared polyethyleneimine-grafted magnetic nanoparticles to dispose sewage, for which the adsorbing

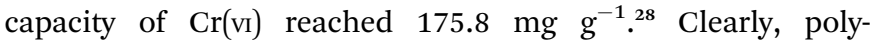
ethylenimine (PEI) whose chain has plenty of primary and secondary amino groups is frequently used to modify sorbents by grafting onto the support materials to improve the adsorption capacity for $\mathrm{Cr}(\mathrm{vI}){ }^{29,30}$ Given that amino groups are easily protonated under acidic conditions, $\mathrm{Cr}(\mathrm{vI})$ could be absorbed on polyethyleneimine-modified adsorbents by electrostatic interaction. However, on account of the high solubility of PEI in aqueous system, it is difficult to recover the polymer when it is directly used to remove $\mathrm{Cr}(\mathrm{vI})$ from effluents, limiting the application of PEI. Hence, enhancing the stability and reusability of PEI is another important issue for current studies.

To overcome the shortcomings mentioned above, a new core-shell/bead-like cellulose@PEI aerogel composite was produced by grafting PEI onto the surface of cellulose hydrogel beads using glutaraldehyde (GLA) as cross-linking agent. This method could not only introduce plenty of amino groups to the surface of cellulose, but also increase the mechanical property of cellulose hydrogels. Meanwhile, the separation of cellulose@PEI aerogel beads after adsorbing chromium is very simple, avoiding tedious procedures like filtration or other separation process. Thus, the synthetic sorbent was utilized for removing $\mathrm{Cr}(\mathrm{vI})$ from effluents. Adsorption experiments were carried out as a function of contact time, $\mathrm{pH}$, initial $\mathrm{Cr}(\mathrm{vI})$ concentration, and more significantly flow rate, inlet concentration of column adsorption to investigate the practical potentiality of such new bead-like aerogel composite under dynamic sorption conditions were conducted out, and possible adsorption mechanism was also investigated thoroughly.

\section{Materials and methods}

\subsection{Materials}

PEI $\left(M_{\mathrm{w}}=600,99 \%\right)$ and $\alpha$-cellulose $(50 \mu \mathrm{m})$ were obtained from Sigma-Aldrich Co., Ltd. Glutaraldehyde solution (50\%) was purchased from Tianjin Guangfu Fine Chemical Industry
Research Institute, China. Ethyl acetate, chloroform, glacial acetic acid, urea, $\mathrm{K}_{2} \mathrm{Cr}_{2} \mathrm{O}_{7}$, ethanol, $\mathrm{LiOH}$ were obtained from Tianjin Kermel Chemical Reagent Corporation, China. tertButanol and acetone, supplied by Sinopharm Chemical Reagent Co., Ltd, China. Deionized water was used throughout this work. All the chemicals were used as-received without any further treatment.

\subsection{Synthesis of cellulose@PEI aerogel beads}

The schematic of synthesizing cellulose@PEI aerogel beads is shown in Scheme 1 . Solvent system of $\mathrm{LiOH} /$ urea $/ \mathrm{H}_{2} \mathrm{O}$ (4.6: $15: 80.4 \mathrm{w} / \mathrm{w})$ was prepared at first. Afterwards, a certain amount of $\alpha$-cellulose ( $4 \mathrm{~g}$ ) was dispersed into $100 \mathrm{~g}$ solvent mixture under violent stirring for $2 \mathrm{~h}$ at room temperature. After that, mixed solution was cooled to $-18{ }^{\circ} \mathrm{C}$ for $2 \mathrm{~h}$, and then dissolved at ambient temperature under magnetic stirring to obtain a transparent cellulose solution. Cellulose hydrogel beads were prepared by added dropwise of the cellulose solution $(4 \%, w / w)$ into a coagulation bath of ethyl acetate/ chloroform/glacial acetic acid $(3: 3: 1 \mathrm{v} / \mathrm{v})$ for $10 \mathrm{~min}$, and then the obtained cellulose beads were transferred into glacial acetic acid solution $(1 \%, w / w)$ for $24 \mathrm{~h}$ for the purpose of solidification. Ethyl acetate/chloroform/glacial acetic acid solution could be collected and reused. Afterwards the cellulose hydrogel beads were separated and repeatedly washed with water to remove extra chemical reagents.

The cellulose hydrogel beads and a certain amount of PEI were then added into $60 \mathrm{~mL}$ deionized water stirring for $1 \mathrm{~h}$ to make it totally dispersed. Next, $40 \mathrm{~mL}$ aqueous glutaraldehyde solution as crosslinking agent was put into the hybrid and agitated for $2 \mathrm{~h}$ to obtain core-shell/bead-like cellulose@PEI hydrogel beads, ${ }^{31}$ followed by washing with deionized water to wash away the residual PEI and glutaraldehyde. The absorbed water in cellulose hydrogel beads was exchanged with ethanol which was then replaced by the tert-butanol. Lastly, cellulose@PEI hydrogels were frozen at $-50{ }^{\circ} \mathrm{C}$ for $12 \mathrm{~h}$, and subjected to freeze-drying at $-50{ }^{\circ} \mathrm{C}$ for $12 \mathrm{~h}$. By varying the amount of PEI $(1,1.5,2,2.5$ and $3 \mathrm{~g})$, five samples of cellulose@PEI aerogel were generated and coded as CPA-1, CPA-1.5, CPA-2, CPA-2.5 and CPA-3, respectively.

Pure cellulose aerogel (CA) was prepared by the same method as a control sample. Moreover, the tert-butanol replacement prior to freeze-drying was conducted out for the sake of ensuring admirable voids and three-dimensional network structure of the aerogel, which would be demonstrated by the characterization analysis as follows.

\subsection{Characterization}

The FT-IR spectra were measured on Nicolet 5700 FT-IR spectroscope (Nicolet, USA) between 4000 and $500 \mathrm{~cm}^{-1}$ using the $\mathrm{KBr}$ pellet technique. The scanning electron microscopy (SEM) and the energy dispersive X-ray spectroscopy (EDX) images were carried out on a Hitachi S-4800 SEM instrument (Hitachi, Japan) to investigate the morphology and structural of composites. Xray photoelectron spectra (XPS) were studied by an ESCALAB MKII X-ray photoelectron spectrometer. It is worth mentioning 


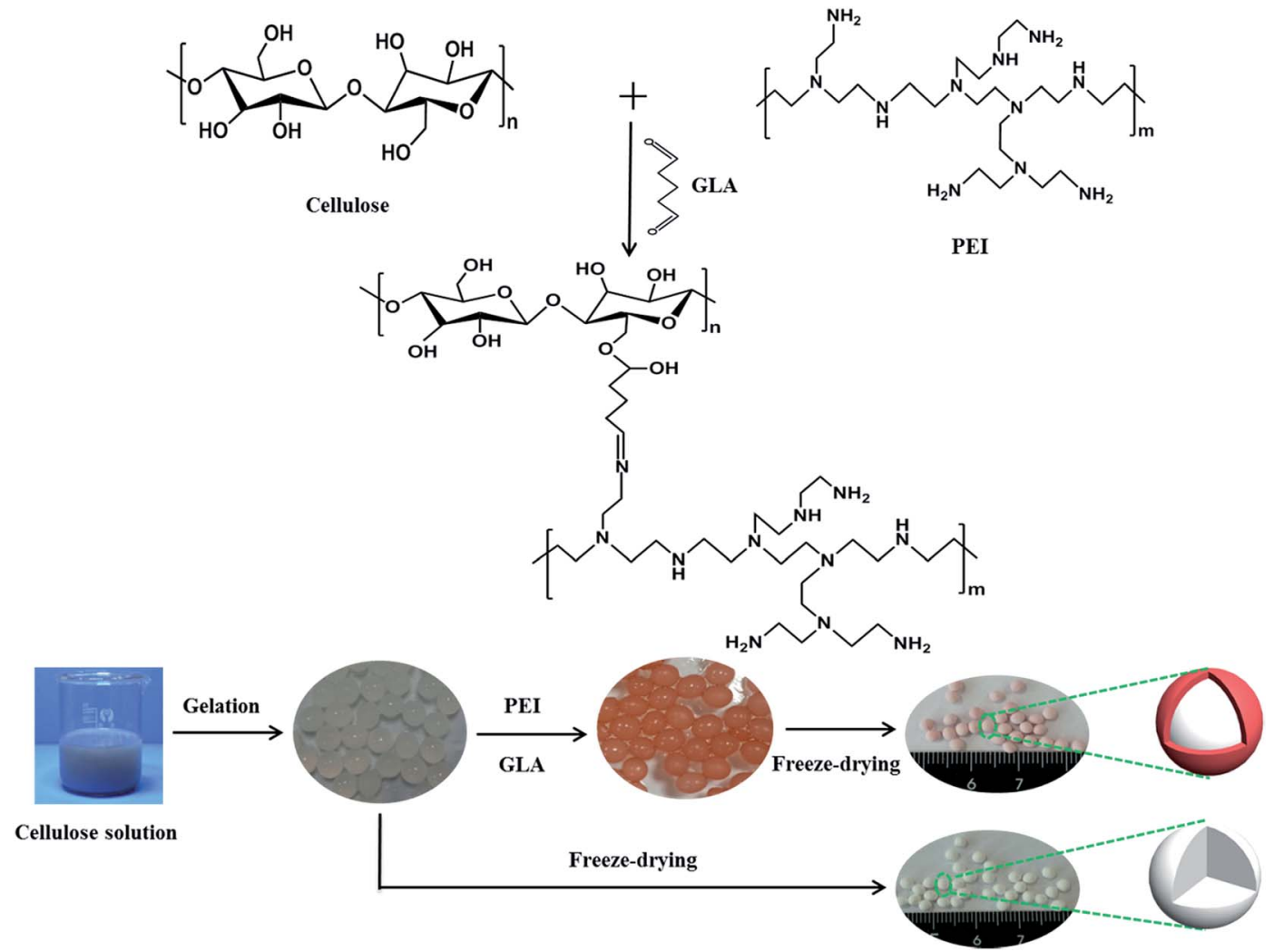

Scheme 1 The synthesis route to prepare cellulose aerogel beads and core-shell cellulose@PEl aerogel beads.

that EDX and XPS were used to confirm the chemical modification process and reveal the adsorption mechanism. The specific surface area and pore diameter were obtained by using a surface area analyzer (Quantachrome Autosorb NOVA2200e, USA). The concentration of $\mathrm{Cr}(\mathrm{vI})$ was measured by a UV-vis spectrophotometer (UV-754N Shanghai, China). All pH values were evaluated by Delta320 digital pH meter (Mettler-Toledo, Switzerland). Moreover, the surface zeta potentials of CPA-2 were studied by Malvern Zen 3600 Zetasizer (Malvern Instruments, United Kingdom) under different pH conditions.

\subsection{Batch adsorption experiments}

A series of batch adsorption experiments including effects of contact time, $\mathrm{pH}$ and initial concentration of $\mathrm{Cr}(\mathrm{vI})$ were conducted in $50 \mathrm{~mL}$ glass conical flasks in which $0.02 \mathrm{~g}$ of sorbent was added into $20 \mathrm{~mL}$ solution of calculated $\mathrm{Cr}(\mathrm{vI})$ concentration by shaking at $180 \mathrm{rpm}$ at $25{ }^{\circ} \mathrm{C}$. Magnetic stirring could ensure the homogeneity of system in adsorption process. Moreover, solution $\mathrm{pH}$ was adjusted by using $0.1 \mathrm{M} \mathrm{HCl}$ or $0.1 \mathrm{M}$ $\mathrm{NaOH}$. Then residual concentration of $\mathrm{Cr}(\mathrm{vI})$ ions was monitored by UV-vis absorption spectrophotometry at maximum absorbance wavelength of $540 \mathrm{~nm}$. And the adsorption capacity at specific times and equilibrium were calculated by the following equations:

$$
q_{t}=\frac{\left(C_{0}-C_{t}\right) V}{m}
$$

$$
q_{\mathrm{e}}=\frac{\left(C_{0}-C_{\mathrm{e}}\right) V}{m}
$$

where $q_{t}\left(\mathrm{mg} \mathrm{g}^{-1}\right)$ and $q_{\mathrm{e}}\left(\mathrm{mg} \mathrm{g}^{-1}\right)$ are the amount of $\mathrm{Cr}(\mathrm{vI})$ adsorbed on cellulose@PEI aerogel beads at time $t$ and equilibrium; $C_{0}, C_{t}$, and $C_{\mathrm{e}}\left(\mathrm{mg} \mathrm{L}^{-1}\right)$ represent the initial, time $t$, and equilibrium concentration of $\mathrm{Cr}(\mathrm{vI})$ solution, respectively; $V(\mathrm{~mL})$ represents the volume of solution; $m(\mathrm{mg})$ represents the adsorbent dose.

\subsection{Column adsorption experiments}

The typical CPA-2 beads with an average size of $3 \mathrm{~mm}$ was packed into the fixed-bed column on account of the bead-like structure of cellulose@PEI aerogel beads, by which was favorable for the dynamic adsorption. Fixed-bed column operations were conducted in glass column whose internal diameter and length were $1.2 \mathrm{~cm}$ and $10 \mathrm{~cm}$, respectively. The column reactors were packed with $0.590 \mathrm{~g} \mathrm{CPA}-2$ at bed depth of $8 \mathrm{~cm}$. Before each experiment, a little gauze was placed at the bottom of fixedbed reactor to make the sorbent stabilized. The concentrations of $\mathrm{Cr}(\mathrm{vI})$ solution fed into the column at a determinate flow rate $\left(1,2\right.$ and $\left.3 \mathrm{~mL} \min ^{-1}\right)$ by a peristaltic pump were 50 and $75 \mathrm{mg} \mathrm{L}^{-1}$, respectively. The samples flowing out were collected at decided time intervals and measured by UV-vis spectrophotometer. The column experiments were used to investigate the practical application properties of adsorbent. The time of breakthrough appearance and the shape of the breakthrough curve are essential features for confirming the dynamic 
response of a fixed-bed column. And the breakthrough curves were drew by ratio of outflow and inlet metal concentration $\left(C_{t} / \mathrm{C}_{0}\right)$ as a function of time. The continuous $\mathrm{Cr}(\mathrm{vI})$ uptake process was continued until the exhaustion point $\left(C_{t} / C_{0}=0.9\right)$ of the column appeared. The outlet concentration from the fixed bed reaching about $10 \%$ of the feed concentration is breakthrough point.

Total adsorbed metal quantity, $q_{\text {total }}(\mathrm{mg})$, is equal to the area under the plot of the adsorbed $\mathrm{Cr}(\mathrm{vI})$ concentration $C_{\text {ad }}\left(C_{\text {ad }}=C_{0}-C_{t}\right)\left(\mathrm{mg} \mathrm{L}^{-1}\right)$ against $t(\mathrm{~min})$, could be calculated using:

$$
q_{\text {total }}=\frac{Q S}{1000}=\frac{Q}{1000} \int_{t=0}^{t=t_{\text {total }}} C_{\text {ad }} \mathrm{d} t
$$

where $Q$ and $t_{\text {total }}$ are the volumetric flow rate $\left(\mathrm{mL} \mathrm{min}^{-1}\right)$ and total flow time (min), respectively. $S$ represents the area under the breakthrough curve. The chromium-polluted water treatment capacity $V_{\mathrm{E}}$ was calculated using:

$$
V_{\mathrm{E}}=Q t_{\mathrm{total}}
$$

The maximum capacity of the fixed bed, $q_{\mathrm{e}}\left(\mathrm{mg} \mathrm{g}^{-1}\right)$, was evaluated from eqn (5):

$$
q_{\mathrm{e}}=\frac{q_{\text {total }}}{X}
$$

where $X(\mathrm{~g})$ is the weight of adsorbent in the column.

Total amount of $\mathrm{Cr}(\mathrm{vI})$ sent to column, $W(\mathrm{mg})$, could be calculated as following:

$$
W=\frac{C_{0} Q t_{\text {total }}}{1000}
$$

Total removal $(R(\%))$ was calculated from eqn (6):

$$
R=\frac{q_{\text {total }}}{W} \times 100
$$

The empty bed contact time (EBCT) is an important parameter. Generally speaking, the $V_{\mathrm{E}}$ is increased with the increase in EBCT. The EBCT in the column can be described as following:

$$
\operatorname{EBCT}(\min )=\frac{\text { bed volume }}{Q}
$$

\section{Results and discussion}

\subsection{Batch adsorption experiments}

3.1.1 Effect of the pH. As we all know, the $\mathrm{pH}$ value of liquid waste is a vital factor in removing metal ions, considering the fact that it could not only influence the charge density of sorbent but also determine $\mathrm{Cr}(\mathrm{vI})$ speciation in effluents. Different $\mathrm{pH}$ values of 1 to 8 were applied for the purpose of researching the optimal $\mathrm{pH}$ for metal ions adsorption process over cellulose@PEI aerogel beads with original Cr(vi) concentrations of $100 \mathrm{mg} \mathrm{L}^{-1}$. Adsorption processes were enforced at ambient temperature and stirring continued for $24 \mathrm{~h}$. The

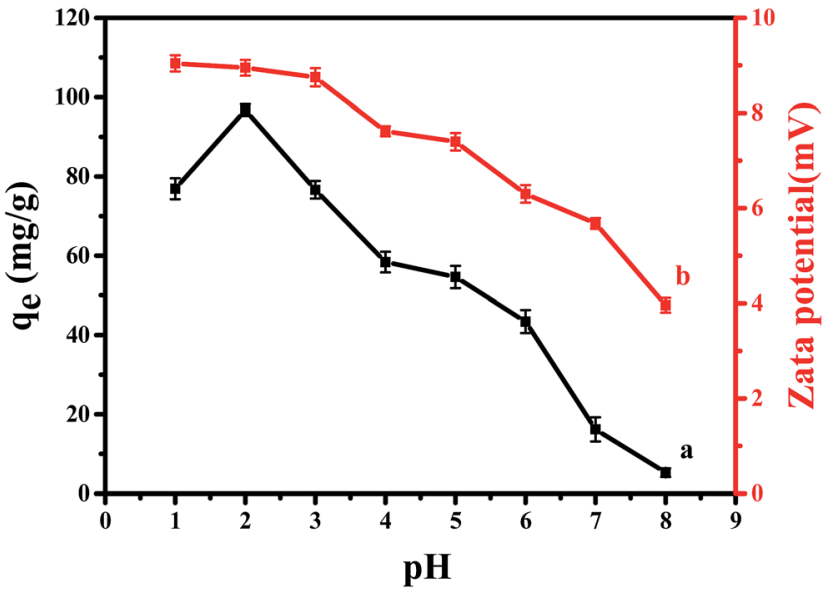

Fig. 1 (a) Effect of $\mathrm{pH}$ on the adsorption of $\mathrm{Cr}(\mathrm{vl})$ on CPA-2; (b) zeta potential analysis at different solution $\mathrm{pH}$ onto $\mathrm{CPA}-2$.

results in Fig. 1a illustrated that the adsorbing capacity of $\mathrm{Cr}(\mathrm{vI})$ increased with the increase of $\mathrm{pH}$ from 1 to 2 , and then decreased with increasing $\mathrm{pH}$ from 2 to 8. Clearly, the maximum adsorbing capacity of $\mathrm{Cr}(\mathrm{vI})$ was $96.8 \mathrm{mg} \mathrm{L}^{-1}$ at $\mathrm{pH}=2$, for which can be selected for the subsequent experiments.

The impact of solution $\mathrm{pH}$ on chromium uptake could be elucidated by the surface charge of sorbent and the degree of ionization of adsorbate. Therefore, the surface charges of CPA-2 were measured at various $\mathrm{pH}$ values. From Fig. 1b, it should be noted that cellulose@PEI composite was positively charged and zeta potential value decreased with increasing $\mathrm{pH}$ from 1 to 8 . The positive charge could be associated with PEI, which is a cationic polyelectrolyte. There are many $-\mathrm{NH}_{2}$ on cellulose@PEI aerogel that would be protonated to form $-\mathrm{NH}_{3}{ }^{+}$in low $\mathrm{pH}$ solution, resulting in an electrostatic attraction to negatively charged $\mathrm{Cr}(\mathrm{vI})$ ions, ${ }^{32}$ which can lead to an increase in adsorption capacity. When the solution $\mathrm{pH}$ increased, the degree of $-\mathrm{NH}_{2}$ protonation decreased, making a decrease in surface charge of CPA-2.

In addition, $\mathrm{Cr}(\mathrm{vI})$ exists various forms such as $\mathrm{H}_{2} \mathrm{CrO}_{4}$, $\mathrm{HCrO}_{4}{ }^{-}, \mathrm{CrO}_{4}{ }^{2-}$ and $\mathrm{Cr}_{2} \mathrm{O}_{7}{ }^{2-}$ in water which are associated with solution $\mathrm{pH}$. The dominant forms of $\mathrm{Cr}(\mathrm{vI})$ would interconvert from $\mathrm{CrO}_{4}{ }^{2-}$ to $\mathrm{HCrO}_{4}{ }^{-}$and $\mathrm{Cr}_{2} \mathrm{O}_{7}{ }^{2-}$ when $\mathrm{pH}$ value is lower than 6.5, while $\mathrm{pH}$ above 6.5 hexavalent chromium could be transformed as $\mathrm{CrO}_{4}{ }^{2-}$. In addition, $\mathrm{H}_{2} \mathrm{CrO}_{4}$ is predominant at $\mathrm{pH}$ less than $2 .^{33}$ In contrast to $\mathrm{CrO}_{4}{ }^{2-}, \mathrm{Cr}_{2} \mathrm{O}_{7}{ }^{2-}$ has the same charge but double $\mathrm{Cr}(\mathrm{vI})$ amount, so does the $\mathrm{HCrO}_{4}{ }^{-}$owing to charge balance, making the uptake capacity increased significantly. In other words, increasing the ratio of $\mathrm{HCrO}_{4}{ }^{-}$and $\mathrm{Cr}_{2} \mathrm{O}_{7}{ }^{2-}$ would give rise to an improvement of $\mathrm{Cr}(\mathrm{vI})$ removal. Moreover, at $\mathrm{pH}<2$, the existence of $\mathrm{H}_{2} \mathrm{CrO}_{4}$ could cause reduction of electrostatic attraction between CPA-2 and $\mathrm{Cr}(\mathrm{vI})$. Consequently, the optimal $\mathrm{pH}$ value appeared at 2, which was consistent with previous work. ${ }^{28}$

3.1.2 Adsorption isotherms. Adsorption isotherms are extremely important in the optimization of adsorbents, due to the fact that it not only can evaluate the adsorbability of adsorbent, but also reveal the interaction between adsorbate and sorbent. Accordingly, the adsorption isotherms were 
investigated with CA, CPA-1, CPA-1.5, CPA-2, CPA-2.5 and CPA-3 over the initial $\mathrm{Cr}(\mathrm{VI})$ concentration range of $10-700 \mathrm{mg} \mathrm{L}^{-1}$ at ambient temperature for $24 \mathrm{~h}$. As shown in Fig. S1, $\dagger$ with the increase of equilibrium $\mathrm{Cr}(\mathrm{vI})$ concentration, sorption capacities of all the composites increased, manifesting that initial concentration of $\mathrm{Cr}(\mathrm{vI})$ ions played an important role in affecting the adsorption capacity. Moreover, the maximum adsorption capacity increased with increasing PEI content because of the increased number of active sites contributed by PEI molecules. That is, the more PEI used in the synthesis process, the more $-\mathrm{NH}_{2}$ would bond on the surface of the cellulose, improving the adsorbing capacity. Nevertheless, when the amount of PEI increased from 2 to $3 \mathrm{~g}$, there was a little increase of $\mathrm{Cr}(\mathrm{VI})$ adsorption on the surface of cellulose@PEI beads. In consideration of the adsorption ability and cost effectiveness in practical applications, CPA-2 was determined as the optimal sorbent for following experiments. Besides, when the original concentration was lower than $125 \mathrm{mg} \mathrm{L}^{-1}$, the residual concentration of chromium after removal by CPA- 2 was inappreciable.

Langmuir and Freundlich models, two famous types of isotherm models, were used to simulate the equilibrium data. Langmuir model is based on the assumption that the

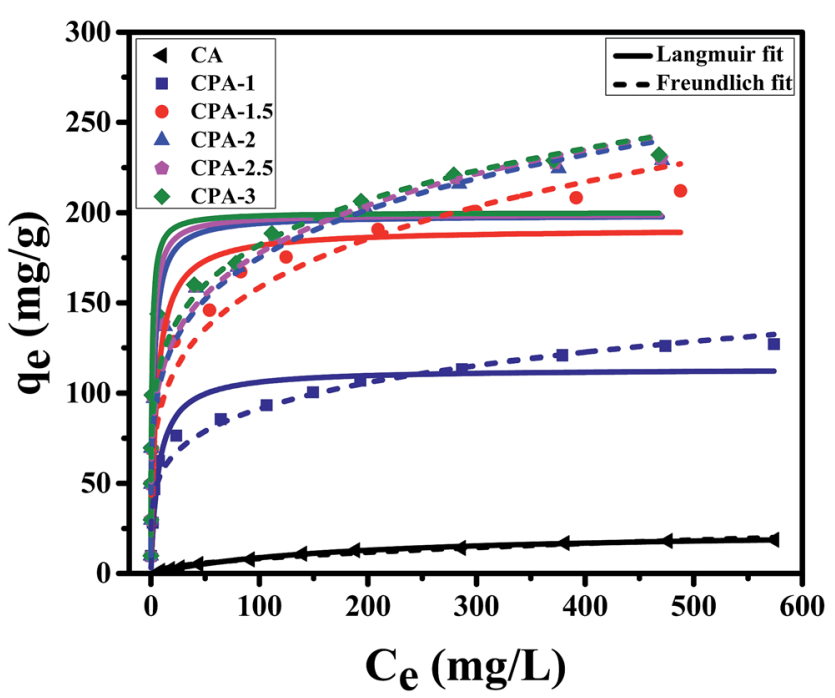

Fig. 2 Langmuir and Freundlich isotherm models of $\mathrm{Cr}(\mathrm{VI})$ removal using CA, CPA-1, CPA-1.5, CPA-2, CPA-2.5 and CPA-3. adsorption process is monolayer sorption on a homogeneous sorption surface and all sorption sites are almost identical. Hence, it can reach saturation. Nevertheless, Freundlich isotherm model is used to characterize multilayer adsorption. ${ }^{34}$ These two models are represented as:

Langmuir:

$$
\begin{aligned}
& q_{\mathrm{e}}=\frac{q_{\mathrm{m}} K_{\mathrm{l}} C_{\mathrm{e}}}{1+K_{\mathrm{l}} C_{\mathrm{e}}} \\
& R_{\mathrm{l}}=\frac{1}{1+K_{\mathrm{l}} C_{0}}
\end{aligned}
$$

Freundlich:

$$
q_{\mathrm{e}}=K_{\mathrm{f}} C_{\mathrm{e}^{\frac{1}{n}}}
$$

where $q_{\mathrm{e}}$ and $C_{\mathrm{e}}$ are the adsorption capacity $\left(\mathrm{mg} \mathrm{g}^{-1}\right)$ and $\mathrm{Cr}(\mathrm{vI})$ concentration $\left(\mathrm{mg} \mathrm{L}^{-1}\right)$ at equilibrium, respectively. $C_{0}$ represents the initial concentration $\left(\mathrm{mg} \mathrm{L}^{-1}\right)$ and $q_{\mathrm{m}}$ represents the maximum adsorbing capacity $\left(\mathrm{mg} \mathrm{g}^{-1}\right) . K_{1}$ represents Langmuir constant $\left(\mathrm{L} \mathrm{mg}^{-1}\right)$ related to the adsorption energy, $K_{\mathrm{f}}$ and $n$ are related to the capacity and intensity of the adsorption, respectively, and $R_{1}$ is Langmuir constant separation factor. The nonlineared adsorption isotherm curves were presented in Fig. 2, and related parameters of the adsorption isotherm models were summarized in Table 1 . The correlation coefficient $R^{2}$ of Freundlich model of all cellulose@PEI composites were higher than that of Langmuir model, suggesting that heterogeneous coverage of target hexavalent chromium on the surface of cellulose@PEI beads. The correlation to the Freundlich model can support the existence of electrostatic interaction between $\mathrm{Cr}(\mathrm{vI})$ and functional groups of CPA-2. ${ }^{35}$ It is worth mentioning that the correlation coefficient $R^{2}$ of Freundlich model and Langmuir model were close. To further analyze the non-lineared adsorption isotherm curves of $\mathrm{Cr}(\mathrm{vI})$, isotherm curves could fit well with Langmuir model when the concentration is low. This phenomenon may be attributed to the electrostatic attraction between protonated $-\mathrm{NH}_{3}{ }^{+}$and $\mathrm{Cr}(\mathrm{vI})$ anions. If $\mathrm{Cr}(\mathrm{vI})$ concentration is low, the surface active sites would dominate the adsorption, making sorption process followed monolayer sorption. When the concentration is higher, the adsorption process followed multilayer adsorption. Interestingly, the adsorption isotherm of chromium onto CA fitted better with

\begin{tabular}{|c|c|c|c|c|c|c|c|}
\hline samples & \multicolumn{4}{|c|}{ Langmuir isotherm } & \multicolumn{3}{|c|}{ Freundlich isotherm } \\
\hline CPA-1 & 113.66 & 0.1421 & $0.0099-0.4131$ & 0.9152 & 34.5086 & 4.7259 & 0.9640 \\
\hline CPA-1.5 & 191.06 & 0.1946 & $0.0073-0.3394$ & 0.9298 & 55.7269 & 4.4056 & 0.9443 \\
\hline CPA-2 & 198.71 & 0.4167 & $0.0034-0.1943$ & 0.8944 & 68.3574 & 4.8976 & 0.9537 \\
\hline
\end{tabular}
Langmuir model, implying a monolayer adsorption process.

Table 1 Langmuir and Freundlich models parameters for $\mathrm{Cr}(\mathrm{VI})$ adsorption on cellulose@PEI beads prepared with varied PEI amount 
From the Freundlich model, it can be observed that adsorption intensity $n>1$, which indicated that the adsorption is favorable. Moreover, the values of $R_{1}$ were between 0 and 1 , revealing the favorable adsorption of $\mathrm{Cr}(\mathrm{vI})$ by cellulose@PEI composites, too.

In addition, the $q_{\mathrm{m}}$ value of CPA-2 for chromium acquired from Langmuir model was $198.7 \mathrm{mg} \mathrm{g}^{-1}$, while the experimental maximum sorption capacity of CPA-2 was $229.1 \mathrm{mg} \mathrm{g}^{-1}$, which was around 12 times higher than the sorption capacity of $\mathrm{Cr}(\mathrm{vI})$ on CA (18.7 $\left.\mathrm{mg} \mathrm{g}^{-1}\right)$, manifesting that the adsorption capacity was observably enhanced by the modification of PEI and considerably higher than other previously reported adsorbents. The $q_{\mathrm{m}}$ values of CPA-2 and other adsorbents under similar conditions were summarized in Table 2 . The CPA- 2 which could be separated from effluents easily had a fairly greater adsorption capacity than those previously reported adsorbents, indicating that CPA-2 has a good potential in the decontamination of chromium-polluted water.

3.1.3 Adsorption kinetics. The effect of contact time on the CPA-2 towards $\mathrm{Cr}(\mathrm{vI})$ ions at two initial concentrations (50 and $100 \mathrm{mg} \mathrm{L}^{-1}$ ) was depicted in Fig. 3. With the increase of concentration (50 to $100 \mathrm{mg} \mathrm{L}^{-1}$ ), the time needed to reach equilibrium increased from 100 to $300 \mathrm{~min}$. The adsorption capacity of CPA-2 increased rapidly and reached almost $90 \%$ in first stage, which took 60-180 min depending on concentrations of $\mathrm{Cr}(\mathrm{vI})$, then the growth trend reduced until the uptake capacity reached saturation. This result suggested that CPA-2 could rapidly adsorb $\mathrm{Cr}(\mathrm{vI})$ from sewage attributing to the properties of the cellulose@PEI composite. Firstly, the porous structure of cellulose aerogel and the strong metal chelating ability of amino group were favorable to the contaction of metal ions and active sites. ${ }^{36}$ Secondly, because of the large molecular weight of PEI, the active amino group was only modified on the surface of material. ${ }^{37}$

As is well known that pseudo-first-order model was based on the assumption that the adsorption process is primarily controlled by internal diffusion process, while the pseudosecond-order kinetic model was based on the assumption that the adsorption process is mainly controlled by chemisorption of adsorbate molecules on active sites. The kinetic data of $\mathrm{Cr}(\mathrm{vI})$ on CPA-2 were fitted by pseudo-first-order and pseudo-secondorder rate equations, ${ }^{38}$ which were expressed as:

Table 2 Comparison of the CPA-2 adsorbent with other materials

\begin{tabular}{lcl}
\hline Adsorbents & $\begin{array}{l}q_{\max } \\
\left(\mathrm{mg} \mathrm{g}^{-1}\right)\end{array}$ & Ref. \\
\hline PEI grafted $\gamma-\mathrm{Fe}_{2} \mathrm{O}_{3} @ \mathrm{Fe}_{3} \mathrm{O}_{4}$ nanoparticles & 78.1 & 48 \\
Activated carbon & 15.5 & 49 \\
Quaternized rice hulls & 32.3 & 50 \\
Amino-functionalized mesoporous silica & 118.6 & 51 \\
PEI immobilized acrylate-based magnetic beads & 140.6 & 28 \\
PEI-HNTs & 102.5 & 27 \\
Amino-functionalized magnetic cellulose & 171.5 & 52 \\
Graphene oxide functionalized with magnetic & 67.7 & 53 \\
PEI-MNPs & 175.8 & 31 \\
CPA-2 & 229.1 & This work
\end{tabular}

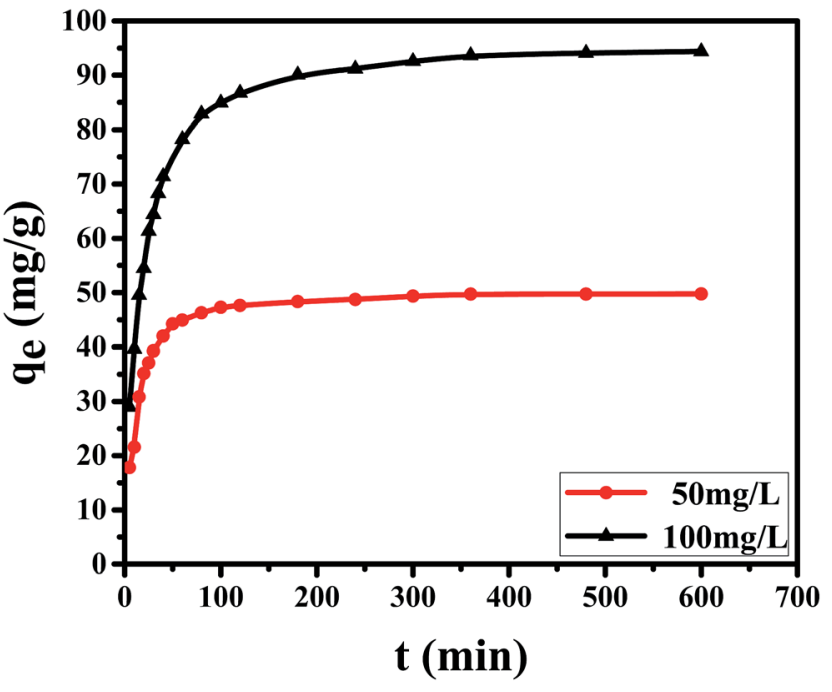

Fig. 3 Influence of contact time on $\mathrm{Cr}(\mathrm{VI})$ removal by CPA-2.

$$
\begin{gathered}
\ln \left(q_{\mathrm{e}}-q_{t}\right)=\ln q_{\mathrm{e}}-K_{1} t \\
\frac{t}{q_{t}}=\frac{1}{K_{2} q_{\mathrm{e}}^{2}}+\frac{t}{q_{\mathrm{e}}}
\end{gathered}
$$

where $q_{\mathrm{e}}\left(\mathrm{mg} \mathrm{g}^{-1}\right)$ and $q_{t}\left(\mathrm{mg} \mathrm{g}^{-1}\right)$ represent the amount of $\mathrm{Cr}(\mathrm{vI})$ adsorbed at equilibrium and time $t$, and $K_{1}\left(\mathrm{~min}^{-1}\right)$ and $K_{2}\left(\mathrm{~g} \mathrm{mg}^{-1} \min ^{-1}\right)$ are pseudo-first-order and pseudo-secondorder rate constant, respectively. The adsorption kinetic model curves were illustrated in Fig. $4 \mathrm{a}$ and b, and corresponding kinetic parameters from both models were listed in Table 3. As indicated in Table 3, the adsorption of $\mathrm{Cr}(\mathrm{vI})$ ions by CPA-2 was considerably better fitted with the pseudo-secondorder kinetic model than the pseudo-first-order kinetic model. The values of $R^{2}$ for the pseudo-second-order kinetic model were 0.9999 for different original concentrations, and the calculated $q_{\mathrm{e}}$ values $\left(q_{\mathrm{e}, \mathrm{cal}}\right)$ of this model agreed with the experimental values (Table 3 ). Based on the assumptions of the pseudo-second-order model, chemisorption between the $\mathrm{Cr}(\mathrm{vI})$ ions and active sites of CPA- 2 was considered to be the rate controlling step in this study.

3.1.4 Effect of coexisting ions and TOC. The effluent generally contains a certain concentration of coexistent cations and anions which could affect the adsorption process of $\mathrm{Cr}(\mathrm{vI}) .^{3}$ As is well known that $\mathrm{Cr}(\mathrm{vI})$ exists in the form of anions in aqueous solution, and the adsorption of $\mathrm{Cr}(\mathrm{vI})$ occurs on the CPA-2 surface by electrostatic interactions. Therefore, the cations would not influent the adsorption process of chromium.

By using $20 \mathrm{mg}$ dosage of CPA-2 and $50 \mathrm{mg} \mathrm{\textrm {L } ^ { - 1 }}(20 \mathrm{~mL})$ as initial $\mathrm{Cr}(\mathrm{vI})$ concentration at $\mathrm{pH} 2$, the adsorption experiments was performed by different concentrations of co-existing anions $\left(\mathrm{Cl}^{-}, \mathrm{NO}_{3}{ }^{-}, \mathrm{F}^{-}, \mathrm{PO}_{4}{ }^{3-}\right.$ and $\left.\mathrm{SiO}_{3}{ }^{2-}\right)$ and TOC (Acid Red 94). The results were depicted in Fig. 5. As shown in the Fig. 5a, the $\mathrm{Cl}^{-}$, $\mathrm{NO}_{3}{ }^{-}$and $\mathrm{F}^{-}$had no remarkable competitive influence on the adsorption of $\mathrm{Cr}(\mathrm{vI})$ onto CPA-2. Nevertheless, the removal capacity for $\mathrm{Cr}(\mathrm{vI})$ decreased rapidly with the increase of the concentration of $\mathrm{PO}_{4}{ }^{3-}$ and $\mathrm{SiO}_{3}{ }^{2-}$. When the concentration of $\mathrm{PO}_{4}{ }^{3-}$ and $\mathrm{SiO}_{3}{ }^{2-}$ increased from 200 to 2000 , the $q_{t}$ of $\mathrm{Cr}(\mathrm{vI})$ 

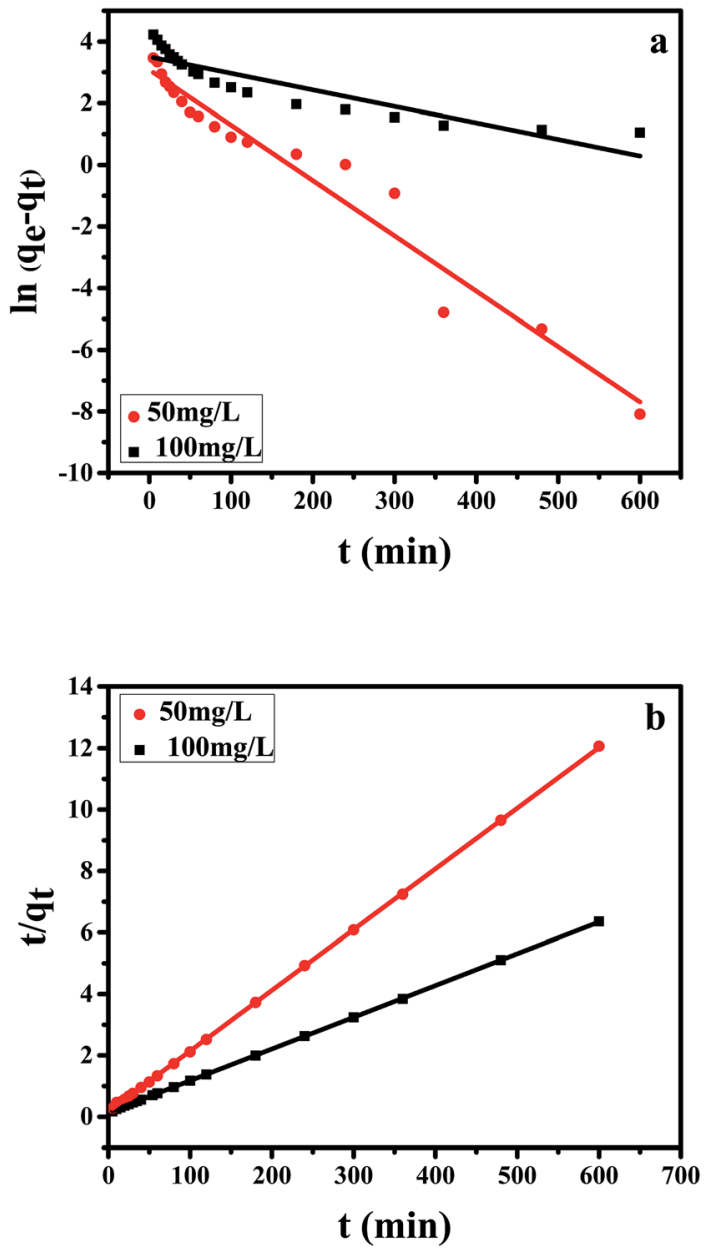

Fig. 4 The (a) pseudo-first-order, (b) pseudo-second-order kinetic model of $\mathrm{Cr}(\mathrm{VI})$ removal on the CPA-2.

decreased from 49.99 to $5.41 \mathrm{mg} \mathrm{L}^{-1}$ and 49.59 to $7.67 \mathrm{mg} \mathrm{L}^{-1}$, respectively. On the one hand, the coexisting $\mathrm{PO}_{4}{ }^{3-}$ and $\mathrm{SiO}_{3}{ }^{2-}$ which can produce $\mathrm{HPO}_{4}{ }^{2-}, \mathrm{HSiO}_{3}{ }^{-}$and $\mathrm{OH}^{-}$under hydrolytic process changed the $\mathrm{pH}$ of aqueous solution. The increased $\mathrm{pH}$ exerted distinct inhibitory effect on the chromates adsorption. On the other hand, competition adsorption could be used to explain the results, too. The $\mathrm{Cl}^{-}, \mathrm{NO}_{3}{ }^{-}$and $\mathrm{F}^{-}$are monovalent anions, which have little competition with $\mathrm{Cr}(\mathrm{vI})$ ions for the active sites on CPA-2. By contrast, $\mathrm{PO}_{4}{ }^{3-}$ and $\mathrm{SiO}_{3}{ }^{2-}$ are multivalent anions. There are distinct competitive effects between the multivalent anions and $\mathrm{Cr}(\mathrm{vI})$. Those results were consistent with the previous works. ${ }^{3,21}$ As can be seen from the Fig. $5 \mathrm{~b}$, the uptake capacity of $\mathrm{Cr}(\mathrm{vI})$ decreased with the increase of TOC.

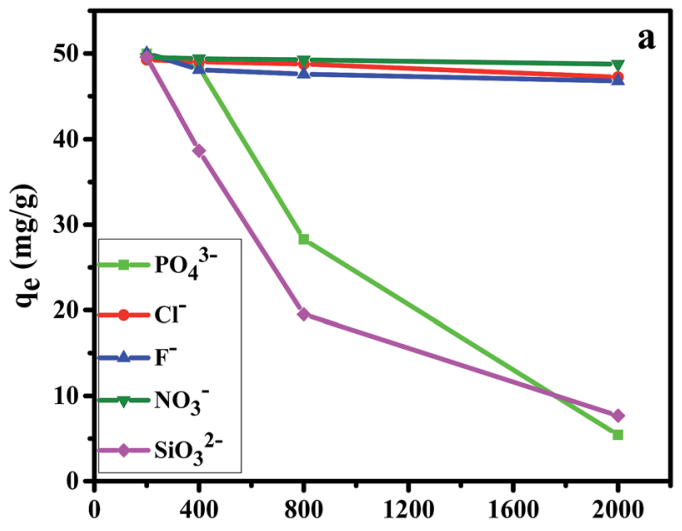

Coexisting anions concentration $(\mathrm{mg} / \mathrm{L})$

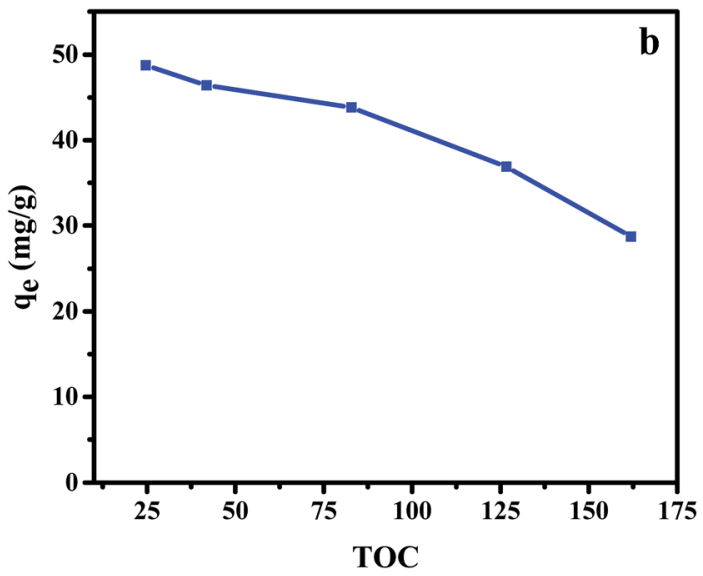

Fig. 5 Effect of coexisting ions and TOC on the adsorption of $\mathrm{Cr}(\mathrm{VI})$ by CPA-2.

When the concentration of TOC increased from 24.66 to 161.92 , the removal capacity of $\mathrm{Cr}(\mathrm{vI})$ decreased from 48.75 to $32.71 \mathrm{mg} \mathrm{L}^{-1}$. The Acid Red 94 is anionic dye that can compete active adsorption sites with $\mathrm{Cr}(\mathrm{vI})$ ions, resulting in the decrease of removal capacity.

3.1.5 Effect of real wastewater. The effect of real wastewater on the CPA-2 towards $\mathrm{Cr}(\mathrm{vI})$ ions in three initial concentrations (50, 100 and $200 \mathrm{mg} \mathrm{L}^{-1}$ ) solution which were prepared by dissolving $\mathrm{K}_{2} \mathrm{Cr}_{2} \mathrm{O}_{7}$ in deionized water and filtered real wastewater was depicted in Fig. 6 . When the initial concentration was $50 \mathrm{mg} \mathrm{L}^{-1}$, the adsorption capacity of deionized water and real wastewater were 49.65 and $48.14 \mathrm{mg} \mathrm{L}^{-1}$, respectively. With the

Table 3 Kinetic parameters for $\mathrm{Cr}(\mathrm{VI})$ adsorption by $\mathrm{CPA}-2$ beads at different initial concentrations

\begin{tabular}{|c|c|c|c|c|c|c|c|}
\hline 100 & 96.76 & 0.0054 & 33.24 & 0.8109 & 0.0007 & 96.81 & 0.9999 \\
\hline
\end{tabular}




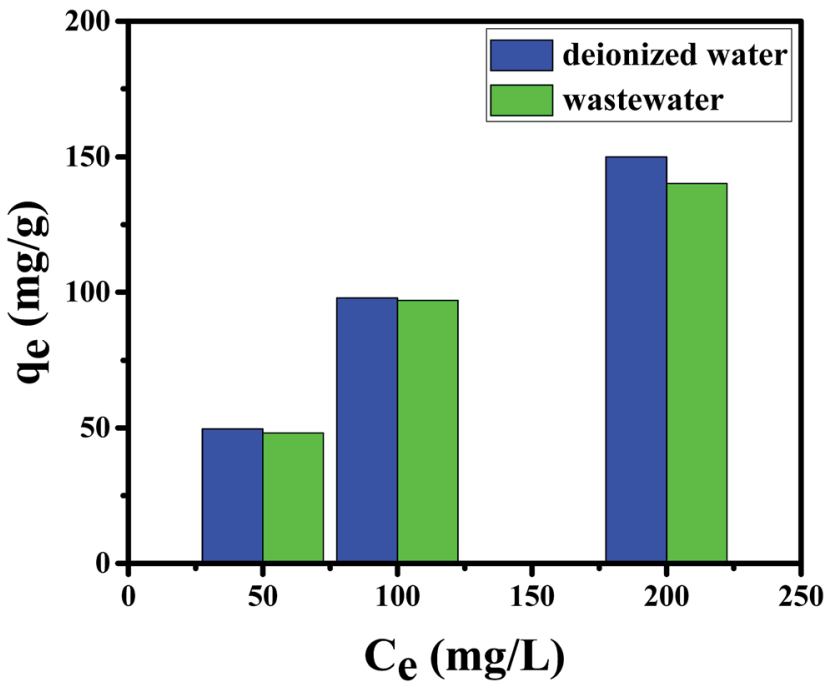

Fig. 6 The effect of deionized water and wastewater on the removal of $\mathrm{Cr}(\mathrm{vl})$.

increase of initial concentrations the adsorption capacities increased, and the sorption capacities of real wastewater slightly lower than deionized water. Although the adsorption capacities were reduced to some extent, the removal capacities of chromium were still remain high. The successful adsorption of real wastewater which include many kinds of ions and organic compounds also indicates that coexisting ions and TOC had no remarkable influence on the adsorption of $\operatorname{Cr}(\mathrm{vI})$ onto CPA-2.

\subsection{Dynamic column adsorption testing}

3.2.1 Effect of flow rate. Three different flow rates of 1,2 and $3 \mathrm{~mL} \mathrm{~min}{ }^{-1}$ were used to investigate the effect of the flow rate on the breakthrough curves of $\mathrm{Cr}(\mathrm{vI})$ with a constant bed depth of $8 \mathrm{~cm}$ and inlet $\mathrm{Cr}(\mathrm{vI})$ concentration of $50 \mathrm{mg} \mathrm{L}^{-1}$ at $\mathrm{pH}$ 2. The breakthrough curves at various flow rates were shown in Fig. 7a and all parameters were presented in Table 4, where it can be seen that the steepness of the breakthrough curves increased with the flow rate increasing. Breakthrough time reaching saturation was occurred more quickly with an increase in the flow rate, as well. The possible reasons behind these are that $\mathrm{Cr}(\mathrm{vI})$ ions have longer time to touch with binding sites on CPA-2 at a low rate of influent, resulting in a greater adsorption of $\mathrm{Cr}(\mathrm{vI})$ in fixed bed; on the contrary, during using the higher flow rate, the mass transfer rate tend to increase and the amount of $\mathrm{Cr}(\mathrm{vI})$ adsorbed on fixed-bed column increased, leading to the saturation point occurred rapidly. Thus, for lower flow rate whose contact time is longer could visibly improve the $\mathrm{Cr}(\mathrm{vI})$ removal efficiency in practical applications.

3.2.2 Effect of inlet $\mathbf{C r}(\mathrm{vI})$ concentration. Initial concentration of $\mathrm{Cr}(\mathrm{vI})$ has important influence on the breakthrough curve owing to stronger driving force is supplied for $\mathrm{Cr}(\mathrm{vI})$ removal by higher $\mathrm{Cr}(\mathrm{vI})$ concentration during the adsorption process. $^{39}$ The sorption breakthrough curves obtained by varying feed $\mathrm{Cr}(\mathrm{vI})$ concentration from 50 to $75 \mathrm{mg} \mathrm{L}^{-1}$ at
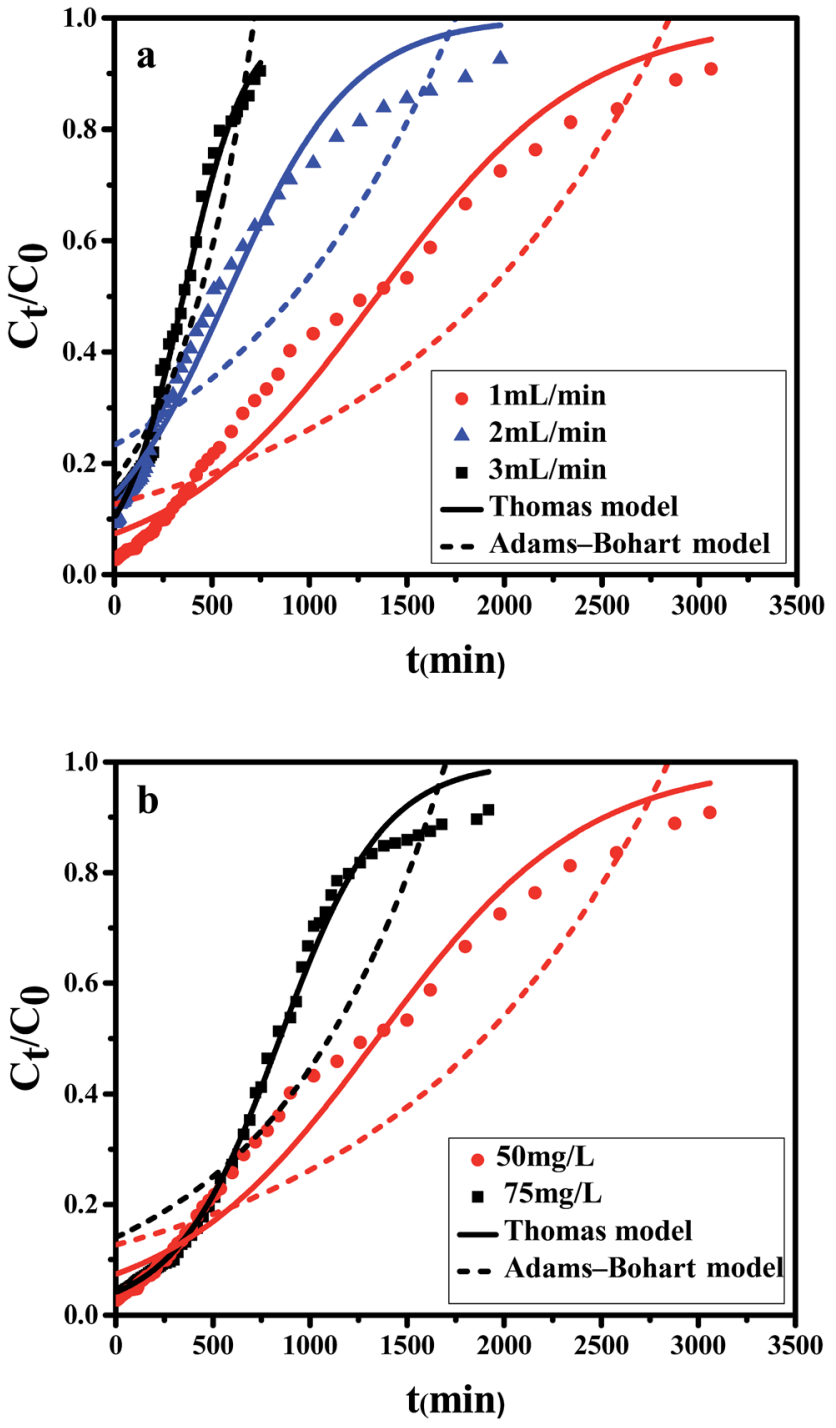

Fig. 7 Experimental and predicted breakthrough curves of $\mathrm{Cr}(\mathrm{VI})$ removal by CPA-2 using fixed-bed (a) different flow rates $\left(C_{0}=\right.$ $50 \mathrm{mg} \mathrm{L}^{-1}, \mathrm{H}=8 \mathrm{~cm}, \mathrm{pH}=2, T=298 \mathrm{~K}$ ); (b) different initial $\mathrm{Cr}(\mathrm{vl})$ concentrations $\left(Q=1 \mathrm{~mL} \mathrm{~min}^{-1}, H=8 \mathrm{~cm}, \mathrm{pH}=2, T=298 \mathrm{~K}\right)$.

$1 \mathrm{~mL} \mathrm{~min}{ }^{-1}$ flow rate, $\mathrm{pH} 2$ and $8 \mathrm{~cm}$ bed height were given in Fig. 7b. Table 4 listed the calculated parameters of $\mathrm{Cr}(\mathrm{vI})$ removal by CPA-2 at different influent concentrations.

It is shown that the slope of breakthrough curve increased with the inlet $\mathrm{Cr}(\mathrm{VI})$ concentration increasing. At lower feed concentration, breakthrough curve was dispersed and saturation point occurred slowly because of the weaker driving force in the mass transfer process. As initial concentration increased, a steeper breakthrough curve was obtained which could be explained by the condition that more hexavalent chromium could be available to bind with the active sites at higher concentration.

3.2.3 Dynamic column adsorption modeling. For the purpose of describing the dynamic behavior of fixed-bed column and scaling up it for industrial applications, AdamsBohart and Thomas models were employed to fit breakthrough curves, ${ }^{40}$ and the calculated parameters of different operating 
Table 4 Column adsorption parameters for $\mathrm{Cr}(\mathrm{VI})$ by CPA-2

\begin{tabular}{llllllr}
\hline$Q\left(\mathrm{~mL} \mathrm{~min}^{-1}\right)$ & $C_{0}\left(\mathrm{mg} \mathrm{L}^{-1}\right)$ & $\mathrm{pH}$ & $W(\mathrm{mg})$ & $t_{\text {total }}(\mathrm{min})$ & $q_{\text {total }}(\mathrm{mg})$ & $\left.q_{\mathrm{e}}(\mathrm{mg} \mathrm{g})^{-1}\right)$ \\
\hline 1 & 50 & 2 & 153 & 3060 & 70.48 & 119.46 \\
2 & 50 & 2 & 198 & 1980 & 36.80 & 62.37 \\
3 & 50 & 2 & 112.5 & 750 & 17.44 & 18.07 \\
1 & 75 & 2 & 144 & 1920 & 66.62 & 112.91
\end{tabular}

conditions were listed in Table 5. The Adams-Bohart model assumes a rectangular isotherm with a quasi-chemical rate expression. Adams-Bohart model which is established on the basis of the surface reaction theory assumes that the balance is not instantaneous, and the adsorption rate depends on the amount of residual adsorbate and adsorbent adsorption capacity. The Thomas model base on Langmuir equation with a pseudo second-order rate expression and assumes that the ideal model without axial diffusion, which can be used to estimate the equilibrium adsorption and adsorption rate constant. The predicted and experimental breakthrough curves of $\mathrm{Cr}(\mathrm{vI})$ uptake by CPA-2 at different flow rate and inlet concentration were shown in Fig. 7.

The Thomas model is one of the most ecumenically applied models for continuous flow systems,${ }^{\mathbf{4 1}}$ which can be expressed as:

$$
\frac{C_{t}}{C_{0}}=\frac{1}{1+e^{\frac{K_{\mathrm{T}} q_{0} M}{Q} K_{\mathrm{T}} C_{0} t}}
$$

in which $C_{0}$ and $C_{t}$ are the feed and outlet $\operatorname{Cr}(\mathrm{vI})$ concentration $\left(\mathrm{mg} \mathrm{L}^{-1}\right), \quad K_{\mathrm{T}}$ represents Thomas model constant $\left(\mathrm{L} \mathrm{min}^{-1} \mathrm{mg}^{-1}\right), q_{0}$ represents the removal capacity $\left(\mathrm{mg} \mathrm{g}^{-1}\right)$, $Q$ is flow rate $\left(\mathrm{mL} \mathrm{min}^{-1}\right)$ and $M$ is the sorbent mass $(\mathrm{g})$.

The Bohart-Adams model was used to fit the initial part of the breakthrough curve, ${ }^{\mathbf{4 2}}$ which was focused on estimating characteristic parameters, such as $N_{0}$ and $K_{\mathrm{AB}}$, and the model was given as follows:

$$
\frac{C_{t}}{C_{0}}=e^{K_{\mathrm{AB}} C_{0} t-K_{\mathrm{AB}} N_{0}} \frac{Z}{F}
$$

in which $K_{\mathrm{AB}}$ represents the kinetic constant $\left(\mathrm{L} \mathrm{min}^{-1} \mathrm{mg}^{-1}\right), N_{0}$ represents the maximum uptake capacity $\left(\mathrm{mg} \mathrm{mL}^{-1}\right), Z$ represents bed depth $(\mathrm{cm})$ and $F$ represents the linear speed $\left(\mathrm{cm} \min ^{-1}\right)$.
As can be seen from the Table 5, for the Thomas model, the uptake capacity $\left(q_{0}\right)$ decreased with the increase of feed concentration or flow rate of $\mathrm{Cr}(\mathrm{vI})$, while the value of $K_{\mathrm{T}}$ increased. Therefore, lower flow rate and inlet concentration would increase the removal of $\mathrm{Cr}(\mathrm{vI})$ on the CPA-2 beads. For the Adams-Bohart model, the values of $K_{\mathrm{AB}}$ increased with inlet concentration or flow rate increasing, while the values of $N_{0}$ decreased with influent concentration or flow rate increasing. These results represented that the system kinetics was controlled by external mass transfer in the initial stage of $\mathrm{Cr}(\mathrm{vI})$ adsorption. By comparing the correlation coefficients $\left(R^{2}\right)$ obtained from all the dynamic models, the correlation coefficient values generated from the Thomas model were much higher than those from the Adams-Bohart model. It was concluded that the Thomas model was more suitable for the processes of $\mathrm{Cr}(\mathrm{vI})$ removal on the CPA-2 under different fixed-bed conditions, while the Bohart-Adams model could be used to fit the initial part of the breakthrough curve.

\subsection{Characterization of resultant materials}

3.3.1 SEM and EDX analysis. The morphology and structure of the CA, CPA-2 and after $\mathrm{Cr}(\mathrm{vI})$ adsorption on CPA-2 (CPA-2-Cr) were investigated by SEM, and Fig. 8a-d showed the desirable three-dimensional network structure of these composites. From the photos, it was observed that PEI observably constringed the pore size of cellulose aerogel, which probably due to PEI molecules grafted on cellulose and partially occupied the interspace among cellulose molecules. However, comparison of the SEM images revealed that the network structure of cellulose aerogel beads has not been damaged by the introduction of PEI and the uptake of $\mathrm{Cr}(\mathrm{vI})$.

Additionally, EDX mapping were used to reveal the element type and content of cellulose aerogel beads. As can be seen, C and $\mathrm{O}$ elements existed in CA beads (Fig. 8e), while $\mathrm{N}$ element

Table 5 Parameters of Adams-Bohart and Thomas models analyzed for $\mathrm{Cr}(\mathrm{VI})$ removal by CPA-2 in column adsorption

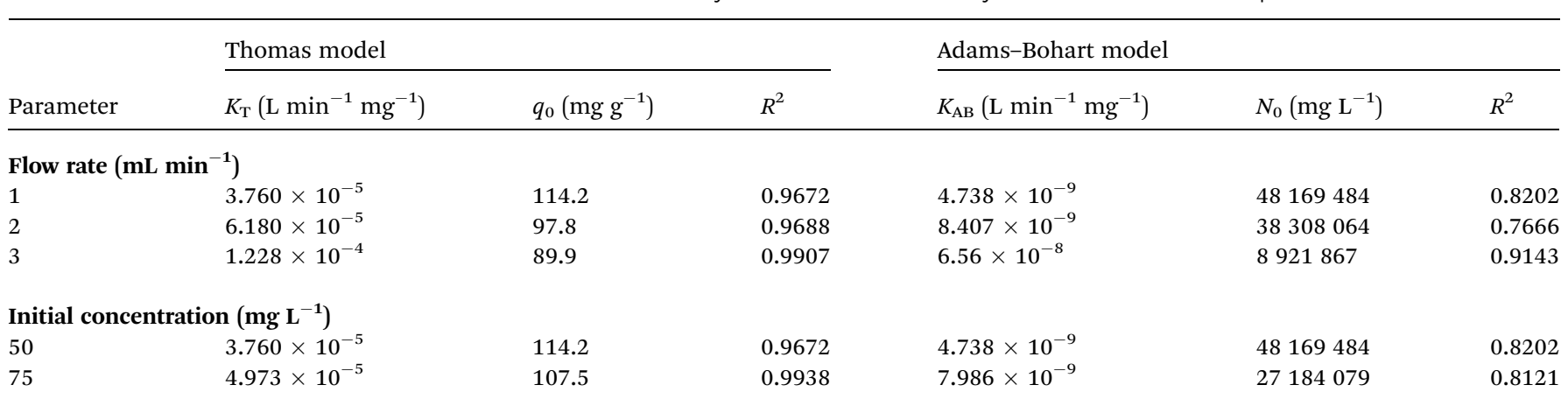




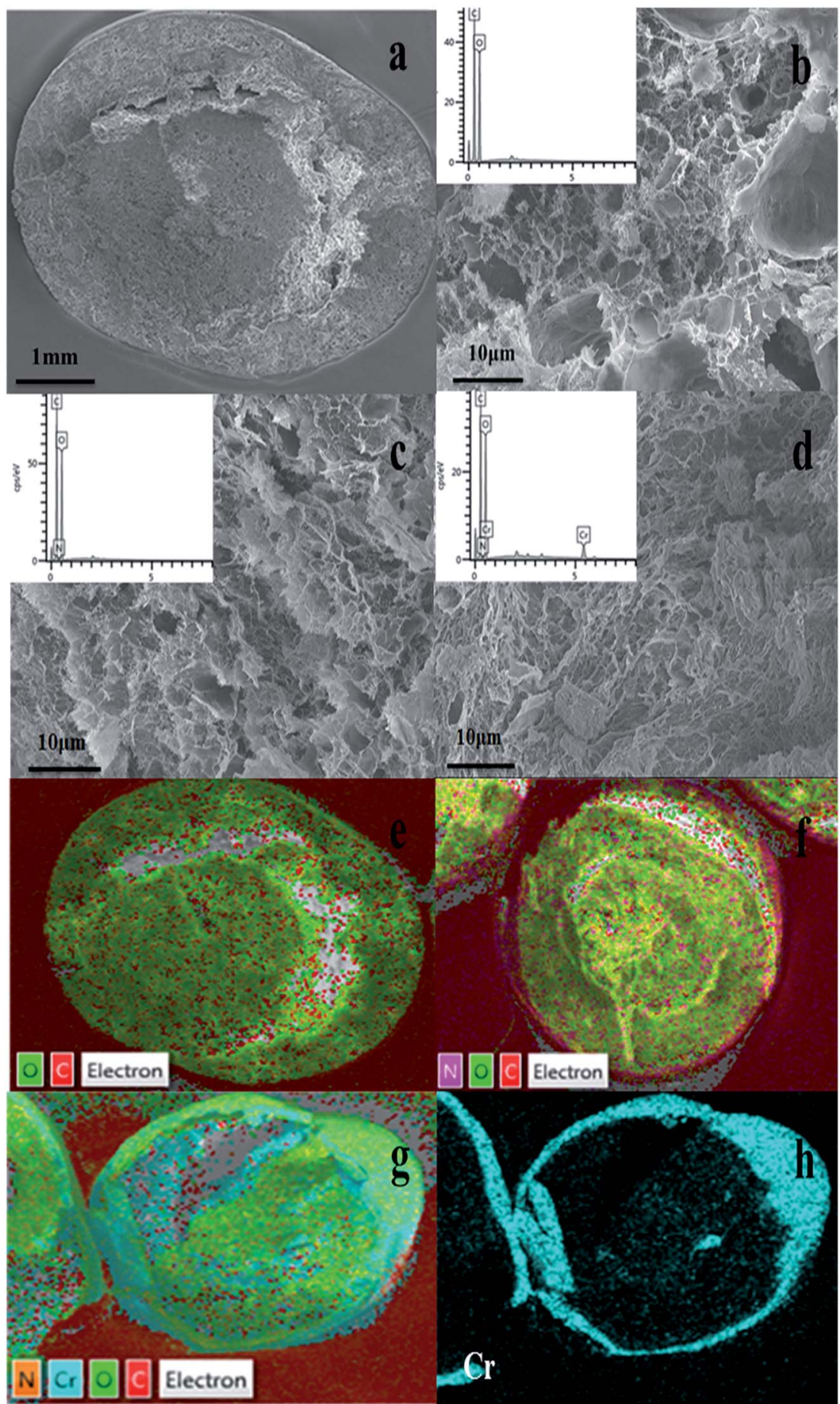

Fig. 8 SEM images of ( $a$, b) CA, (c) CPA-2, (d) CPA-2-Cr; EDX pattern of (e) CA, (f) CPA-2, (g, h) CPA-2-Cr (insets show EDX pattern of element type and content of CA, CPA-2 and CPA-2-Cr).

was detected in CPA-2 (Fig. 8f). Given that there are amount of amino groups on PEI molecules, the existence of $\mathrm{N}$ element indicated that PEI had been grafted on CA beads resoundingly which was proved by the following XPS analysis. As depicted in Fig. $8 \mathrm{~g}$ and $\mathrm{h}$, the existence of $\mathrm{Cr}$ was obviously observed on the surface of CPA-2-Cr, demonstrating that $\mathrm{Cr}(\mathrm{VI})$ ions have been absorbed on the surface of adsorbent under testing conditions. In addition, other EDX spectra (Fig. 8b-d insets) clearly displayed the change of element type and content of CA, CPA-2 and CPA-2-Cr.

3.3.2 FTIR analysis. The functional groups of CA, CPA-2 and CPA-2-Cr were characterized by FTIR spectroscopy, and the typical spectra were shown in Fig. 8. The characteristic peaks of CA (Fig. 9a) appeared at $3444 \mathrm{~cm}^{-1}$ and $2921 \mathrm{~cm}^{-1}$, belonging to the stretching vibrations of $\mathrm{O}-\mathrm{H}$ and $\mathrm{C}-\mathrm{H}$ bonds. ${ }^{43}$ The adsorption peak at $1160 \mathrm{~cm}^{-1}$ corresponded to the $\mathrm{C}-\mathrm{O}$ 


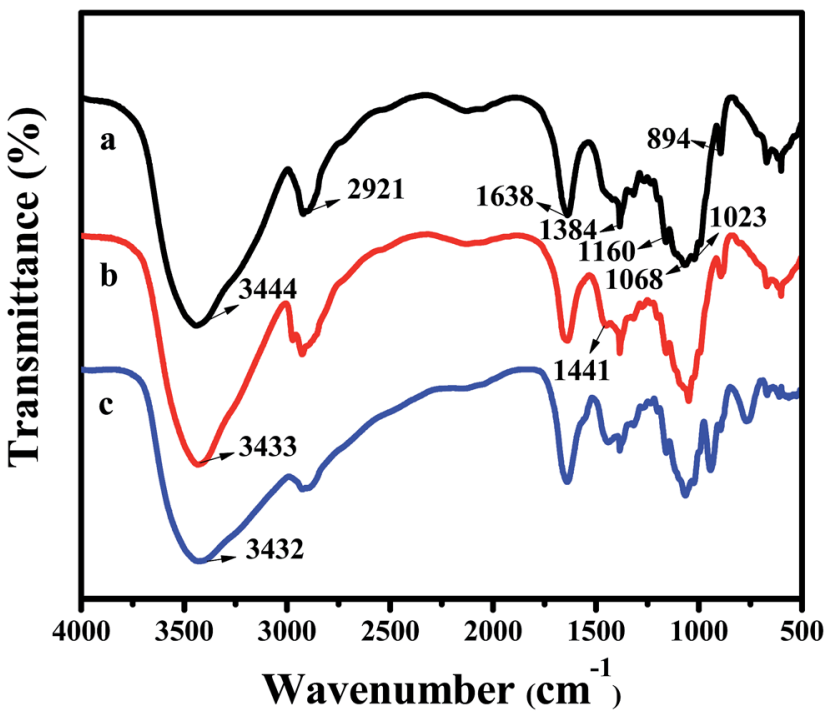

Fig. 9 FT-IR spectra of (a) CA, (b) CPA-2 and (c) CPA-2-Cr.

stretching vibrations. The bands at $1023 \mathrm{~cm}^{-1}$ and $1068 \mathrm{~cm}^{-1}$ were assigned to the $\mathrm{C}-\mathrm{O}-\mathrm{C}$ pyranose ring skeletal vibrations. ${ }^{44}$ The peak located at $1638 \mathrm{~cm}^{-1}$ corresponded to the bending mode of absorbed water..$^{45}$ The band at $1384 \mathrm{~cm}^{-1}$ related to the bending vibrations of hydroxyl groups and the peak at $894 \mathrm{~cm}^{-1}$ may be attributed to the $\beta$-glucosidic linkages between the sugar units in cellulose. ${ }^{46}$ After modification of porous cellulose with PEI, the broad peak at about $3400 \mathrm{~cm}^{-1}$ become wider and stronger in Fig. 9b, which could be assigned to the superposition of the stretching vibrations of $\mathrm{O}-\mathrm{H}$ and $\mathrm{N}-\mathrm{H}$ groups. Moreover, the new band appeared at $1441 \mathrm{~cm}^{-1}$ represented the $\mathrm{C}-\mathrm{N}$ vibrations. These results confirmed that amino groups were introduced onto the cellulose surface and the adsorbent of core-shell/bead-like CPA-2 was successfully synthesized. In the spectrum of CPA-2-Cr (Fig. 9c), the adsorption peaks at $3400 \mathrm{~cm}^{-1}$ and $2920 \mathrm{~cm}^{-1}$ were weakened, indicating that the amino and hydroxyl groups of the surface of CPA-2 played an important role in the uptake process.

3.3.3 BET analysis. The relevant textural parameters of CA and CPA-2 calculated from nitrogen adsorption-desorption isotherms were summarized in Table S1. $\dagger$ It revealed that the BET surface area of CPA-2 $\left(36.77 \mathrm{~m}^{2} \mathrm{~g}^{-1}\right)$ was slimly smaller than that of CA $\left(41.7 \mathrm{~m}^{2} \mathrm{~g}^{-1}\right)$. The average pore sizes of CA and CPA-2 were approximately 13.7 and $13.5 \mathrm{~nm}$, respectively. The results mentioned above are in agreement with SEM, and the most likely cause is that PEI molecules were grafted on CA hydrogels which blocked some pores, again suggesting that PEI
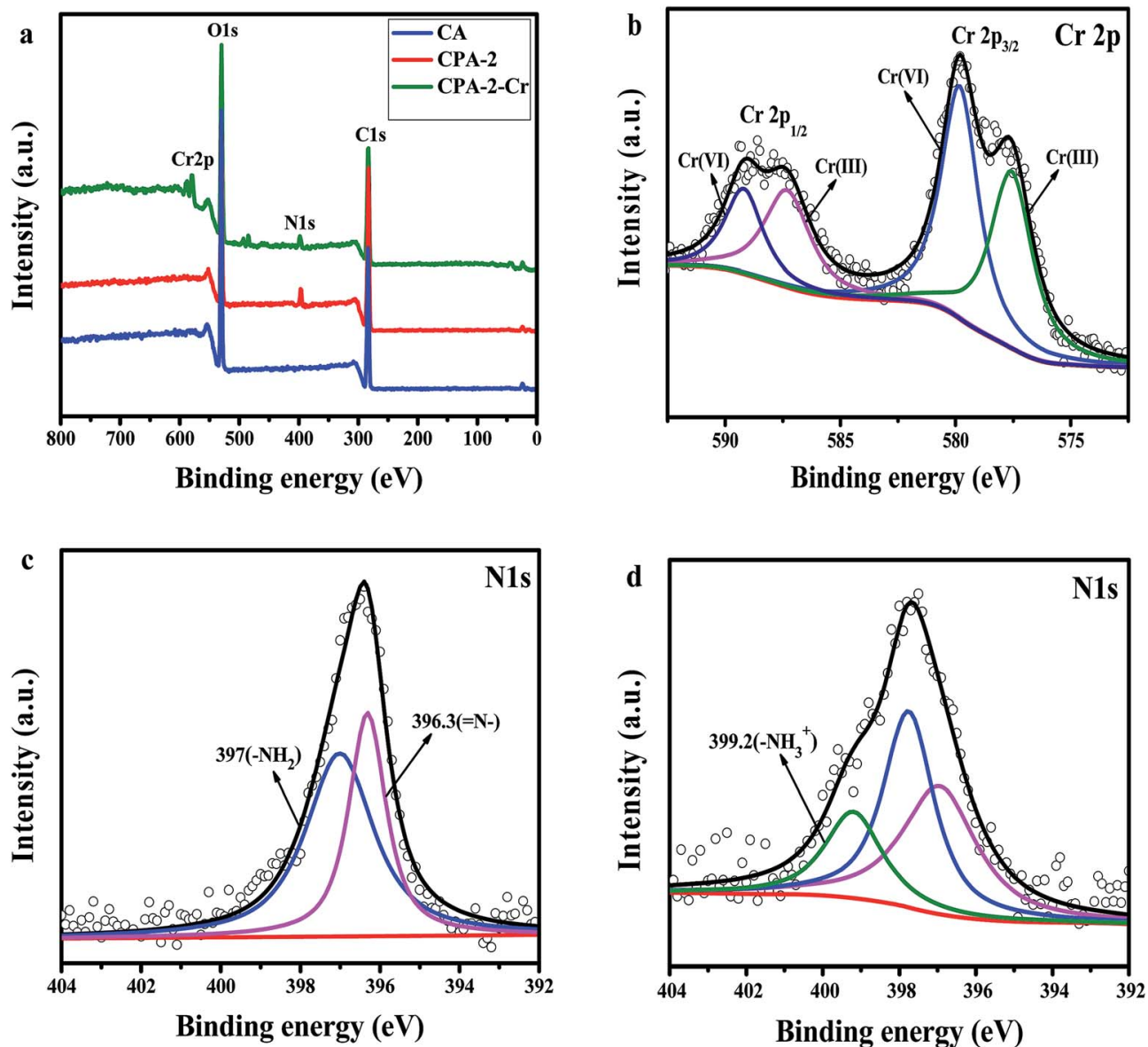

Fig. 10 XPS spectra of (a) total survey spectra of CA, CPA-2 and CPA-2-Cr, (b) Cr 2p spectrum of CPA-2-Cr, (c) N 1s spectra of CPA-2, (d) N 1s spectra of CPA-2-Cr. 
had been successfully grafted onto CA. As seen in Fig. S2, $\uparrow$ CA and CPA-2 exhibited a typical type IV curves with hysteresis loops, which is typical for mesopore material. The mesopore structure is favorable for mass transfer between sorbent and hexavalent chromium.

\subsection{Adsorption mechanism over resultant sample}

Through the $\mathrm{pH}$ effect study, it is known that the sorption process is regarded as the result of electrostatic interaction between protonated amine group $\left(-\mathrm{NH}_{3}{ }^{+}\right)$and $\mathrm{Cr}(\mathrm{vI})$ ions. For the advanced investigation of the adsorption mechanism, XPS spectra of CA, CPA-2 and CPA-2-Cr were studied and the spectra were shown in Fig. 10. As illustrated in the XPS total survey spectra (Fig. 10a), the photoelectron lines of CA at binding energies of about 285 and $533 \mathrm{eV}$ were related to $\mathrm{C} 1 \mathrm{~s}$ and $\mathrm{O} 1 \mathrm{~s}$, respectively. The existence of $\mathrm{N}$ element in the CPA-2 was demonstrated by the peak in the wide scan spectrum with binding energy at $400 \mathrm{eV}$. For the spectrum of CPA-2-Cr, there were two peaks at 579 and $588 \mathrm{eV}$ appeared, which related to $\mathrm{Cr}$ $2 \mathrm{p}_{3 / 2}$ and $\mathrm{Cr} 2 \mathrm{p}_{1 / 2}$ orbits, respectively, demonstrating that $\mathrm{Cr}(\mathrm{vI})$ was successfully adsorbed by CPA-2. All these results were in accordance with the EDX and FTIR analyses. The highresolution $\mathrm{Cr} 2 \mathrm{p}$ spectrum could be split into four peaks (Fig. 10b). The peaks at $577.6 \mathrm{eV}\left(\mathrm{Cr} 2 \mathrm{p}_{3 / 2}\right)$ and $587.3 \mathrm{eV}\left(\mathrm{Cr} 2 \mathrm{p}_{1 / 2}\right)$ were assigned to $\mathrm{Cr}(\mathrm{III})$ and the others at $579.8 \mathrm{eV}\left(\mathrm{Cr} 2 \mathrm{p}_{3 / 2}\right)$ and $589.1 \mathrm{eV}\left(\mathrm{Cr} 2 \mathrm{p}_{1 / 2}\right)$ were ascribed to $\mathrm{Cr}(\mathrm{vI})$, demonstrating that $\mathrm{Cr}(\mathrm{VI})$ and $\mathrm{Cr}(\mathrm{III})$ coexist on the porous surface of CPA-2. ${ }^{47}$
The removal of chromium was generally depended on the functional groups on the surface of sorbent. Fig. 10c and d displayed the $\mathrm{N}$ 1s spectra of CPA-2 before and after $\operatorname{Cr}(\mathrm{vI})$ adsorption. In Fig. 10c, the peaks at 396.3 and $397 \mathrm{eV}$ were attributed to $=\mathrm{N}$ - and $-\mathrm{NH}_{2}$, respectively. After adsorbing $\mathrm{Cr}(\mathrm{vI})$, as shown in Fig. 8d, the new peak appeared at $399.2 \mathrm{eV}$ assigned to $-\mathrm{NH}_{3}{ }^{+}$, and the peaks of $=\mathrm{N}$ - and $-\mathrm{NH}_{2}$ had corresponding shift, indicating that amino groups from PEI participated in the $\mathrm{Cr}(\mathrm{vI})$ removal process.

From the above analysis, the mechanism of $\mathrm{Cr}(\mathrm{vI})$ removal could be concluded as follows; on the one hand, the amino groups on the adsorbent could be effectively protonated to $-\mathrm{NH}_{3}{ }^{+}$at lower $\mathrm{pH}$, and $\mathrm{Cr}(\mathrm{vI})$ anions were adsorbed on CPA-2 via electrostatic attraction. On the other hand, $\mathrm{Cr}(\mathrm{vI})$ was reduced to less toxic $\mathrm{Cr}(\mathrm{III})$ by a redox reaction occurred between $\mathrm{Cr}(\mathrm{vI})$ and CPA-2. The existence of amino and hydroxyl groups acting as electron donors could be responsible for the reduction of $\mathrm{Cr}(\mathrm{vI})$ to $\mathrm{Cr}(\mathrm{III})$ during the adsorption process. Most of the Cr(III) immobilized on CPA-2 surface through ion exchange or surface complexation and a few of residual $\mathrm{Cr}$ (III) were released to solution again. The proposed removal mechanism was depicted in Scheme 2.

\subsection{Regeneration studies}

Desorption and regeneration experiments were designed to assess the practical utility of CPA-2, due to reusability is important for adsorbent to decrease economic cost. To do so,

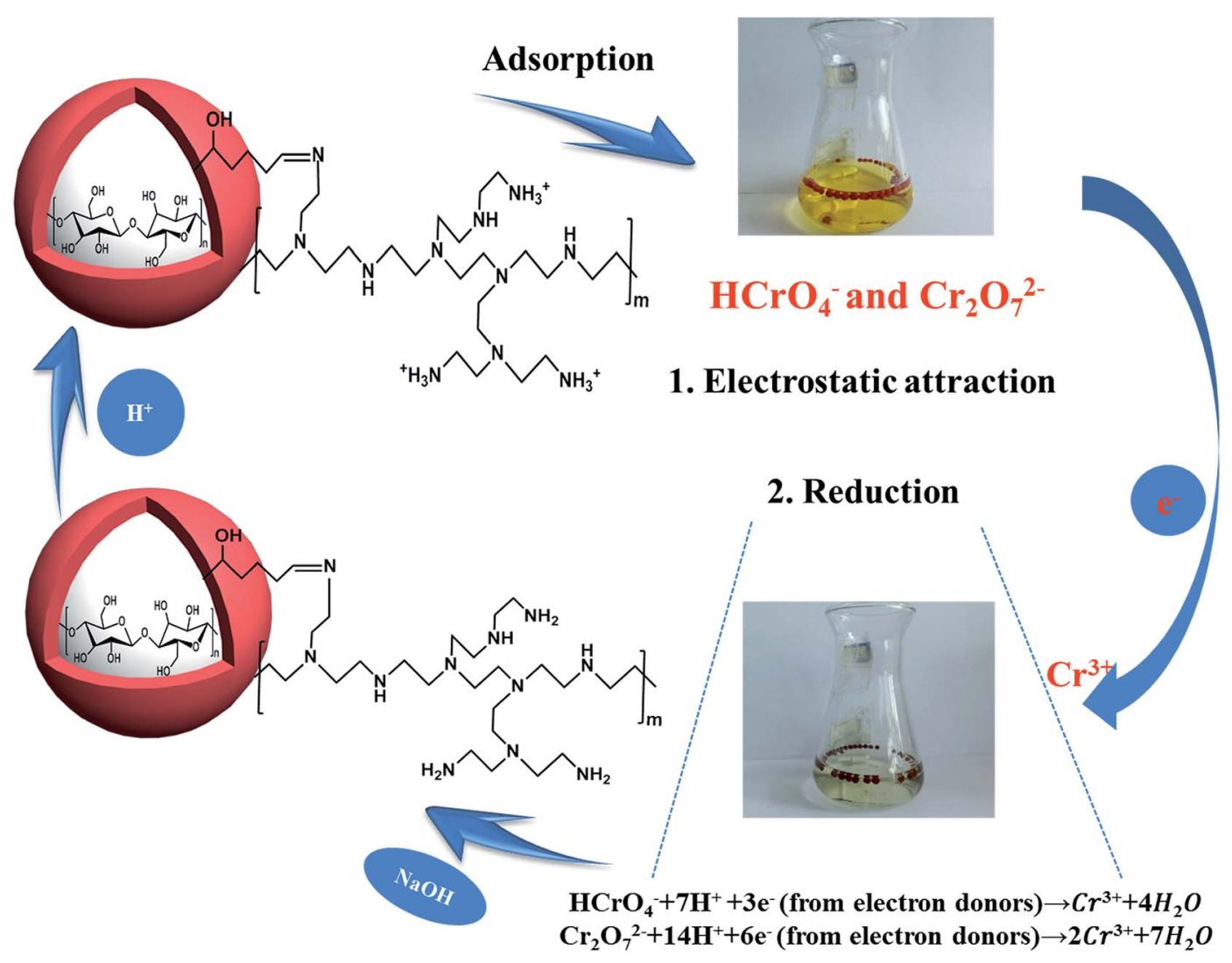

Scheme 2 The mechanism for the removal of $\mathrm{Cr}(\mathrm{vI})$ by CPA-2. 


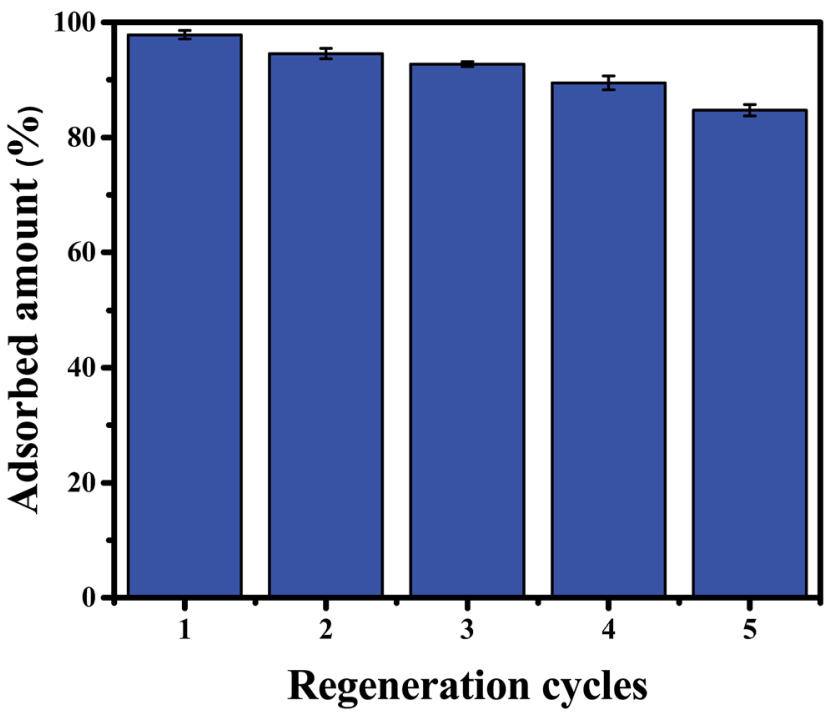

Fig. 11 The reusability of CPA-2 for the adsorption of $\mathrm{Cr}(\mathrm{VI})$.

$0.02 \mathrm{~g}$ CPA-2 beads was added into $20 \mathrm{~mL}$ of $50 \mathrm{mg} \mathrm{L}^{-1} \mathrm{Cr}(\mathrm{vI})$ solution by shaking at $180 \mathrm{rpm}$ at $25{ }^{\circ} \mathrm{C}$ for $24 \mathrm{~h}$. The $\mathrm{Cr}(\mathrm{vI})-$ adsorbed CPA-2 beads were collected and eluted for $30 \mathrm{~min}$ using $50 \mathrm{~mL}$ of a solution of $0.2 \mathrm{~mol} \mathrm{~L}^{-1} \mathrm{NaOH}$ and $0.2 \mathrm{~mol} \mathrm{~L}^{-1}$ $\mathrm{NaCl}$, and then rinsed with deionized water to $\mathrm{pH}$ 6-7 for reuse in the second run. After five adsorption-desorption cycles, the removal efficiency still kept above $80 \%$ (Fig. 11), indicating that CPA-2 beads could be repeatedly utilized in removing $\mathrm{Cr}(\mathrm{vI})$ from effluents. The decrease in adsorption capacity could be attributed to the loss of partial reduction property of CPA-2 and the unavoidable mass loss during the cyclic process.

\section{Conclusion}

In conclusion, a new type of low-cost, highly efficient, environmentally-friendly bead-like composite (CPA-2) was synthesized through cross-link reaction between the amine groups of PEI and the hydroxyl groups of cellulose, leading to the significant enhancement of $\mathrm{Cr}(\mathrm{vI})$ removal efficiency under batch and column systems. Either morphology analysis or changes of FTIR and XPS characteristic spectra demonstrated the successful modification of CPA-2 with PEI. The batch experimental results indicated that $\mathrm{Cr}(\mathrm{vI})$ adsorption capacity of CPA-2 was highly $\mathrm{pH}$ dependent, and the optimal $\mathrm{pH}$ value appeared at 2 . The maximum adsorption capacity of CPA-2 was calculated to be $229.1 \mathrm{mg} \mathrm{g}^{-1}$, which was much higher than previous reported adsorbents for $\mathrm{Cr}(\mathrm{vI})$ removal. Kinetics data suggested that the removal of $\mathrm{Cr}(\mathrm{vI})$ on CPA-2 fitted well with pseudo-second-order kinetic model while the equilibrium data were well described by Freundlich model. Column studies indicated that the adsorption of $\mathrm{Cr}(\mathrm{vI})$ on CPA-2 depended on flow rate and influent $\mathrm{Cr}(\mathrm{VI})$ concentration, and Thomas model was more suitable for the breakthrough curves of adsorption processes under different fixed-bed conditions. Mechanism investigations revealed that the removal of chromium by the CPA-2 was a complicated process, in which electrostatic interaction and a redox reaction were involved. More significantly, the CPA-2 beads could be easily separated and reused without significant loss of adsorption capacity even after five cycles. Generally speaking, as-prepared CPA-2 can be considered as a promising adsorptive material in the decontamination of chromium-polluted water.

\section{Conflicts of interest}

There are no conflicts to declare.

\section{Acknowledgements}

We acknowledge the financial support from the National Natural Science Foundation of China (21676039) and the Opening Foundation of State Key Laboratory of Inorganic Synthesis and Preparative Chemistry of Jilin University (201604) for this work.

\section{References}

1 H. Gu, S. Rapole, Y. Huang, D. Cao, Z. Luo, S. Wei and Z. Guo, J. Mater. Chem. A, 2013, 1, 2011-2021.

2 R. Anderson, Regul. Toxicol. Pharmacol., 1997, 26, S35-S41.

3 W. Zheng, Q. An, Z. Lei, Z. Xiao, S. Zhai and Q. Liu, RSC Adv., 2016, 6, 104897-104910.

4 X. Lv, J. Xu, G. Jiang, J. Tang and X. Xu, J. Colloid Interface Sci., 2012, 369, 460-469.

5 T. Liu, Z. Wang, L. Zhao and X. Yang, Chem. Eng. J., 2012, 189, 196-202.

6 L. Keith, Environ. Sci. Technol., 1979, 13, 416-423.

7 S. Rengaraj, C. Joo, Y. Kim and J. Yi, J. Hazard. Mater., 2003, 102, 257-275.

8 R. Goyal, N. Jayakumar and M. Hashim, J. Hazard. Mater., 2011, 195, 383-390.

9 J. Dui, G. Zhu and S. Zhou, ACS Appl. Mater. Interfaces, 2013, 5, 10081-10089.

10 P. Hu, X. Liang, M. Yaseen, X. Sun, Z. Tong, Z. Zhao and Z. Zhao, Chem. Eng. J., 2018, 332, 608-618.

11 L. Lin, S. Zhai, Z. Xiao, Y. Song, Q. An and X. Song, Bioresour. Technol., 2013, 136, 437-443.

12 L. Zhang, W. Xia, X. Liu and W. Zhang, J. Mater. Chem. A, 2015, 3, 331-340.

13 X. Lei, X. Xue and H. Yang, Appl. Surf. Sci., 2014, 321, 396403.

14 B. Saha and C. Orvig, Coord. Chem. Rev., 2010, 254, 29592972.

15 A. Albadarin, C. Mangwandi, A. Al-Muhtaseb, G. Walker, S. Allen and M. Ahmad, Chem. Eng. J., 2012, 179, 193-202.

16 D. Mulange Wa Mulange and A. Garbers-Craig, J. Hazard. Mater., 2012, 223-224, 46-52.

17 Y. Fan, R. Yang, Z. Lei, N. Liu, J. Lv, S. Zhai, B. Zhai and L. Wang, Korean J. Chem. Eng., 2016, 33, 1416-1424.

18 A. Kumar, S. Kalidhasan, V. Rajesh and N. Rajesh, Ind. Eng. Chem. Res., 2012, 51, 58-69.

19 B. Adhikari, M. Gurung, S. Alam, B. Tolnai and K. Lnoue, Chem. Eng. J., 2013, 231, 190-197. 
20 Y. Yan, Q. An, Z. Xiao, W. Zheng and S. Zhai, Chem. Eng. J., 2017, 313, 475-486.

21 R. Li, Q. An, Z. Xiao, B. Zhai and S. Zhai, RSC Adv., 2017, 7, 40227-40236.

22 C. Liu, R. Jin, X. Ouyang and Y. Wang, Appl. Surf. Sci., 2017, 408, 77-87.

23 H. Qiao, Y. Zhou, F. Yu, E. Wang, Y. Min, Q. Huang, L. Pang and T. Ma, Chemosphere, 2015, 141, 297-303.

24 X. Xiong, J. Duan, W. Zou, X. He and W. Zheng, J. Membr. Sci., 2010, 363, 96-102.

25 L. Zhao and H. Mitomo, J. Appl. Polym. Sci., 2008, 110, 13881395.

26 Y. Zhao, H. Shen, S. Pan, M. Hu and Q. Xia, J. Mater. Sci., 2010, 45, 5291-5301.

27 X. Tian, W. Wang, Y. Wang, S. Komarneni and C. Yang, Microporous Mesoporous Mater., 2015, 207, 46-52.

28 B. Chen, X. Zhao, Y. Liu, B. Xu and X. Pan, RSC Adv., 2015, 5, 1398-1405.

29 Y. Pang, G. Zeng, L. Tang, Y. Zhang, Y. Liu, X. Lei, Z. Li, J. Zhang, Z. Liu and Y. Xiong, Chem. Eng. J., 2011, 175, 222-227.

30 A. Donia, A. Atia and F. Abouzayed, Chem. Eng. J., 2012, 191, 22-30.

31 G. Bayramoğlu and M. Arica, Chem. Eng. J., 2008, 139, 20-28.

32 G. Zhao, J. Li, X. Ren, C. Chen and X. Wang, Environ. Sci. Technol., 2011, 45, 10454-10462.

33 X. Sun, Y. Ma, X. Liu, S. Wang, B. Gao and X. Li, Water Res., 2010, 44, 2517-2524.

34 Q. Cao, F. Huang, Z. Zhuang and Z. Lin, Nanoscale, 2012, 4, 2423-2430.

35 R. Yu, Y. Shi, D. Yang, Y. Liu, J. Qu and Z. Z. Yu, ACS Appl. Mater. Interfaces, 2017, 9, 21809-21819.

36 D. Setyono and S. Valiyaveettil, J. Hazard. Mater., 2016, 302, 120-128.
37 X. Sun, L. Yang, Q. Li, Z. Liu, T. Dong and H. Liu, Chem. Eng. J., 2015, 262, 101-108.

38 L. Zhuang, Q. Li, J. Chen, B. Ma and S. Chen, Chem. Eng. J., 2014, 253, 24-33.

39 J. Goel, K. Kadirvelu, C. Rajagopal and V. Garg, J. Hazard. Mater., 2005, 125, 211-220.

40 Q. Li, X. Tang, Y. Sun and H. Xu, RSC Adv., 2015, 5, 2533725347.

41 H. Thomas, J. Am. Chem. Soc., 1944, 66, 1664-1666.

42 Y. Liu, G. Zhong, Z. Liu, M. Meng, Y. Jiang, L. Ni, W. Guo and F. Liu, RSC Adv., 2015, 5, 85691-85704.

43 L. Yun, H. Liu, R. Gao, S. Xiao, Z. Ming, Y. Yin, S. Wang, L. Jian and D. Yang, ACS Appl. Mater. Interfaces, 2016, 8, 29179-29185.

44 J. Sun, X. Sun, H. Zhao and R. Sun, Polym. Degrad. Stab., 2004, 84, 331-339.

45 W. Li, A. Jin, C. Liu, R. Sun, A. Zhang and J. Kennedy, Carbohydr. Polym., 2009, 78, 389-395.

46 Z. Du, T. Zheng, P. Wang, L. Hao and Y. Wang, Bioresour. Technol., 2016, 201, 41-49.

47 H. Liang, X. Cao, W. Zhang, H. Lin, F. Zhou, L. Chen and S. Yu, Adv. Funct. Mater., 2011, 21, 3851-3858.

48 Y. Pang, G. Zeng, L. Tang, Y. Zhang, Y. Liu, X. Lei, Z. Li, J. Zhang, Z. Liu and Y. Xiong, Chem. Eng. J., 2011, 175, 222-227.

49 S. Babel and T. Kurniawan, Chemosphere, 2004, 54, 951-967.

50 K. Low, C. Lee and A. Ng, J. Environ. Sci. Health, Part A: Environ. Sci. Eng. Toxic Hazard. Subst. Control, 1997, 23, 1849-1860.

51 J. Li, X. Miao, Y. Hao, J. Zhao, X. Sun and L. Wang, J. Colloid Interface Sci., 2008, 318, 309-314.

52 X. Sun, L. Yang, Q. Li, J. Zhao, X. Li, X. Wang and H. Liu, Chem. Eng. J., 2014, 241, 175-183.

53 L. Li, L. Fan, M. Sun, H. Qiu, X. Li, H. Duan and C. Luo, Colloids Surf., B, 2013, 107, 76-83. 